\title{
Chapter 3 \\ Why the Mainstream Economic Paradigm \\ Cannot Inform Sustainability \\ Transformations
}

The theory they developed is known as neoclassical economics. Today it still forms the basis of orthodox theory, and makes up the core curriculum taught to future economists and business leaders in universities and business schools around the world. As a set of ideas, it might be the most powerful in modern history.

David Orrell, Economyths: Ten Ways Economics Gets it Wrong (2010: 13).

Wherever we look around the world, conventional economic thinking remains the principal source of solutions. Somehow, it is suggested, we must find ways of harnessing those forces that have got us into such trouble-self-interest and greed, harnessed to technology - to get us out.

Chandran Nair, Consumptionomics: Asia's Role in Reshaping Capitalism and Saving the Planet (2011: 62).

Economic thought did not adjust to the changed conditions it helped to create; thereby it continued to legitimate, and indeed directly to cause, massive and rapid ecological change. The overarching priority of economic growth was easily the most important idea of the twentieth century.

J.R. McNeill, Something New Under the Sun (2001: 336).

Long before I discovered Polanyi, my decision to study political economy was a key turning point in my quest to find an answer to the question of why we, collectively, do not create the sustainable world that we, as individuals, wish for. While finishing a degree in media and communications, (surely, I thought, "we just need to get the information out!') I added sociology, psychology, political science and global governance to my courses in order to understand the gap between knowledge and practice that I had detected. It was, however, a seminar on macroeconomics that made me feel I was coming closer to understanding why sustainability remains merely an aspiration. This discipline seemed to be devoid of all the insights that I had taken away from the humanities and social sciences.

I will never forget how I was taught the Heckscher-Ohlin theorem, for example. It explains why countries with low wages specialize in labor-intensive production and those with high wages develop production that requires more capital. Because of the factor price advantage of, for example, fisheries (more capital needed) over 
agriculture (more labor intensity possible), a country with easily accessed capital would focus on fishing and scale down its agricultural sector, and a country with cheap labor would prioritize farming over trawling. As a consequence they would quickly benefit: convert the boats into farms and up shoot the exports. In the calculations for the basic model, this conversion is assumed to be free of costs and involve a workforce that instantly migrates to wherever work is available. When I asked if its adherents really believed that people would not find it very costly to uproot their entire way of life simply because of the current terms of trade, the professor gave me a stunning response: "Oh dear, a warm heart speaking."

Confused as to why a cold heart was a good thing, or at least a prerequisite for believing in mainstream economic models, I used my $\mathrm{PhD}$ to study theory of science and the history of economic thought as well as global political economy, institutionalism theories and the role of law. I continued to be drawn into what I described as the reflexive approaches that I put emphasis on with the concept of materiality of ideas in Fig. 2.5.

In the summary of Chap. 2, I discussed the way that the term 'ideas' captures more than simple flashes of thought, mere slogans or buzzwords. This chapter is about zooming in on some ideas that have been instrumental in shaping the processes and systems we live in today. According to Morten Bøås and Desmond McNeill, who have researched the role of ideas in the forming of institutions, these ideas have "some reputable intellectual basis," but they "may nevertheless be found vulnerable on analytical and empirical grounds." What is special about such ideas, they argue, is that they are "able to operate in both academia and policy domains" (Bøås/McNeill 2004: 1).

In the following I will identify some key ideas that, if changed, could induce a paradigm shift and thus trigger a very high leverage point in unlocking unsustainable path dependencies. I think the Brundtland Commission was already at this point when it urged for the "need to integrate economic and ecological considerations in decision making" because this is how the workings of the real world operate. The commission also pointed out that this will "require a change in attitudes and objectives and in institutional arrangements at every level" (WCED 1987: 55). So this chapter seeks to improve futures literacy: people's capacity to imagine futures that are not based on hidden, unexamined, and sometimes flawed assumptions about present and past systems. It hopes to serve the spirit of jointly tackling the structures and path dependencies that keep us, collectively, from bringing about the sustainable world that we, individually, wish for and have agreed to guide our policies toward.

As stated earlier, my goal is not to provide a detailed historical assessment of theoretical and methodological intricacies but to show how strong the influence of some basic economic ideas born in the Enlightenment era remains in decision-making and its rationalization or justifications today. This is why I zoom in on a few key concepts that are customarily applied when deciding how to put the goals of sustainable development into practice: delivering on the needs of current generations while safeguarding the means of need satisfaction for future ones. The 1992 Rio Declaration included the agreement that such development should 
prioritize two key points. These were "the concept of 'needs,' in particular the essential needs of the world's poor," to whom, it argued, "overriding priority should be given" and "the idea of limitations imposed by the state of technology and social organization on the environment's ability to meet present and future needs" (WCED 1987: 41).

To reach these goals the Brundtland Commission urged that: "Human laws must be reformulated to keep human activities in harmony with the unchanging and universal laws of nature" (WCED 1987: 271). We will see that mainstream economic theory does not provide much understanding as to how to do this but rather offers concepts that keep us blind to these key points. The urge to 'integrate' environmental, social and economic concerns led to the expansion of the economic mind-set into the governance of ever more areas of life. This effect has been called the 'economization' of societies and its ongoing trending reifies unsustainable path dependencies instead of helping to unlock them. So it is at least as important to limit the realm of issues to which economics are applied as it is to update the entire discipline.

So to what questions do economists claim to provide answers? Perhaps the most widely used and accepted definition was coined by Lionel Robbins, the famous London School of Economics professor who wrote in 1932 that "Economics is the science which studies human behaviour as a relationship between ends and scarce means which have alternative uses" (Robbins 1932: 15). Such alternative uses are also called 'competing ends' and Robbins argues that the only situations that fall under economic consideration are those in which choices between ends (going to the opera, sleeping or baking bread) need to be taken because the means (time or resources) are limited. Hence, economic situations are those in which some wants need to be relinquished. This means that economics can explain choice making, but cannot shed light on either ends or means. In fact, it was the aim of Robbins' essay to limit the concerns addressed by economics.

This focus is reflected in the key ideas and concepts that it puts forward and that I have summarized in Table 3.1.

All the ideas in the left column clearly fit into the overarching Enlightenment movement that started in the seventeenth century. Its ambition to free humanity from superstitious, theological, and natural limitations to progress generated a rather mechanistic-additive view of systems and the world. Each of the economic

Table 3.1 Mainstream economic paradigm effects on searching for sustainable development

\begin{tabular}{|l|l|l|}
\hline Understanding the world by & Main concepts human needs & Main concepts nature \\
\hline$\ldots$ dividing into pieces & utility by consumption & natural capital by extraction \\
\hline$\ldots$ quantifying \& monetizing & willingness to pay & market prices \\
\hline more happiness through more & $\begin{array}{l}\text { more growth through more } \\
\text { (efficient) exploitation }\end{array}$ \\
\hline consumption & cost-benefit thinking & capital substitutability thinking \\
\hline Effects on governing the world: & Blind to real gualities of developments \& lost in financialization \\
\hline
\end{tabular}

Source Own overview 
concepts in the second and third column of this table can best be understood by remembering that they were born in an era when

- the emphasis lay on the human intellect and its capacity to dissect complex processes and investigate them empirically;

- natural scientism and its law-like predictions of developments replaced religion as the prime source of explanations of the world;

- discourse around natural limits to population size met an energy revolution that fuelled the managerial-industrial drive to improve productivity; and

- the securing of private property and pursuit of self-interest became basic tenets of citizens' freedom and were declared important drivers of progress.

Modernity and neoclassical economic developments of the twentieth century have continued to employ the same mechanistic-additive view and basic concepts, pushing quantified modeling and its extrapolating predictions into yet more dominance when computation made massive calculations possible. There is no emphasis on a deep or diversified understanding of the ends that transactions should serve (human need satisfaction) or the scarce means that are required (nature's resources). These are subsumed into the container terms 'utility' and '(natural) capital.' This is in line with Robbins' definition and understandable when reflecting back on the context in which these concepts were born. Saturation with goods and services was reserved for a very small part of the population and poverty was widespread. It was rational to equate more with better. Meanwhile, in a world of one billion people with plenty of 'undiscovered' territories, there was simply no expectation that more effective exploitation of nature would threaten its health and existence.

From a transformation point of view it is thus easily understood why the Enlightenment movement claimed the term 'liberalism': its ideas inspired collective action toward overcoming an old system that no longer delivered (as far as Enlightenment protagonists were concerned). The premise was to overcome the 'dark' epoch of the Middle Ages. These ideas were key aspects of a paradigm shift that first challenged the old order and its legitimizing narrative and later, as Polanyi showed, served as the gelling consensus between philosophers, scientists, businessmen, politicians and even church representatives working on alternative institution-building and rule-formulation. Polanyi also concluded that imagining all of society as one big market system and treating humans, nature, and money as fictitious commodities inevitably leads to sustainability problems.

So here we come to an interesting question: if Robbins says that the application of economic concepts should be limited to situations of exchanges and choice making but Polanyi argues that all aspects of the planet have been subsumed under the imaginary and logic of a market system, where does the application of economics end? Having analyzed current discourse and observed the marketization and privatization trends of the last 30 years I would say that their application is almost ubiquitous - and that is precisely the problem. It means that neither ends nor means become the center of attention and investigation. Instead, it focuses only on the choice-making of selfishly calculating and insatiable individuals. The 250 -year-old 
innovation of reorganizing all of society around endless gain goals remains unchallenged.

Yet, we now know that there are limits to individual gain, all the more so on a planet with nine to ten billion inhabitants. We also know that the notion that having more means feeling better or happier very much depends, in reality, on the circumstances. Surely, when we seek transformational changes toward sustainable development we cannot use a theory that has not integrated these contextual changes in its concepts? The pursuit of endless gain, as Polanyi points out, had never before in history been "raised to the level of justification of action and behavior in everyday life" (ibid 1957: 30). So it seems obvious both that it is time to repurpose our societies again and that we cannot accept a theory that cannot inductively inform but only deductively reinterpret civilizational changes to fit the universal concepts it has thought up.

Any new Great Transformation needs a different guiding paradigm if its outcome is to improve sustainability. A paradigm that puts needs (ends) and nature (means) center stage instead of hiding them in container terms. One that embraces some empiricism and qualitative reasoning once more. We need a Second Enlightenment fit for what is now known to be a very complex and full world. Luckily, natural and social sciences have moved on and freed themselves from the ideals of positivist-deductive reasoning and quantitative measuring that accompanied modernity. Only mainstream economics has fallen strangely behind in this evolution.

This chapter deals with that evolution. It runs through the columns of the table and first discusses the origins and applications of the concepts for understanding and organizing human need satisfaction, and then the origins and applications of the concepts for understanding and engaging with nature. The subchapters argue that the concepts are insufficient for any transformational sustainable development agenda and are in fact instrumental in perpetuating an unsustainable development path. Then I will add brief overviews of what twenty-first century social sciences, humanities, psychology, neurosciences, quantum physics and also alternative sub-strands of economics say that fills the black boxes of human needs and nature's laws.

\subsection{How Mainstream Economics Views Human Needs and Their Satisfaction}

How do we satisfy the needs of current generations while safeguarding resources for future generations? First we must understand people, their needs and what motivates them to do certain things. Mainstream economics does not make much use of the term 'needs' but has instead adopted the concept of 'utility.'

The term was invented by the philosopher Jeremy Bentham (1748-1832), who described human existence as being based on a hedonic calculus or continuous 
hedonic flow of pleasure or pain. The prime goal of existence was to maximize happiness calculated as the sum of pleasure minus pain. Thus the utility of a certain product or practice expresses a cost-benefit or pain-pleasure trade-off calculation that people undertake when making choices. Since there is no such thing as one 'util,' the numerical formula became money: the purchase decisions of people indicate what they want and the price indicates how highly it ranks on their list of preferences. This willingness to pay expresses the utility and thus happiness they gain from consumption of, for example, ice cream, and the loss of what they give up for it, for example, money or their skills in lawn mowing.

This way of measuring utility through willingness to pay was also called 'working with revealed preferences.' It allowed for the building of mathematical, thus scientific models. Combined with the assumption that humans are insatiable when it comes to happiness or utility, this became the first 'law' of the human condition. It also supports the basic premise of ubiquitous and eternal scarcity (scarce means) that Robbins's 1932 definition of economics carries: since our wants are endless we are constantly worried about how to get more of them satisfied and where we will find those resources. For Robbins, this means not only natural and material resources but also services that are per se limited. His definition restricts the path for need satisfaction - e.g., eating or leisure - entirely to market relations: "Both the services of cooks and the services of opera dancers are limited in relation to demand and can be put to alternative uses" (ibid.: 15).

In this paradigm, trading and bartering are the essence of all relationships. Human existence means constantly improving one's balance sheet. In order for this model to work, it is assumed that actors undertake this improvement rationally, although this paradigm has a very narrow definition of rationality: it is understood as knowing all possible strategies available in a particular situation, knowing the outcomes of each of those - including the behavior of others - and ranking all of the possible outcomes according to the preferences as measured by utility (money).

So all relationships with other humans and nature are driven by the hedonic calculus and thus best governed by markets. The societal vision of a market system is born. The basic 'law' of this system is that of supply and demand. It suggests that, given unlimited wants, every product and service will always find a customer once the price is right. This law has resulted in the famous prediction that markets will always tend toward equilibrium: if I cannot get satisfying prices any longer (demand goes down or too many competitors are around), I will reduce production (supply goes down).

On these two laws all models of mainstream economics have been built. The impact of the Enlightenment movement has been studied by several scholars. David Orrell, Canadian mathematician and author of Economyths. Ten Ways Economics Gets it Wrong, muses: "Just as Newton believed that matter is made up of minute particles that bump off one another but are otherwise unchanged, so mainstream theory assumes that the economy is made up of unconnected individuals who interact by exchanging goods and services and money but are otherwise unchanged" (Orrell 2010: 13). 
Eric Beinhocker, the director of the Institute for New Economic Thinking at Oxford, tells the story of Walras, the mastermind of market equilibrium models. Inspired by his father's declaration that one of the great challenges remaining from the nineteenth century was a scientific theory of economics, Walras spent 14 years working toward a mathematical theory that built on Bentham's utility and the related law of supply and demand to make economic systems predictable. After presenting his market equilibrium equations, Walras concluded that his "pure theory of economics is a science which resembles the physio-mathematical sciences in every respect" (Beinhocker 2007: 36, citing Walras).

Beinhocker explains that models built on these laws do not capture what science knows about behavior, decision-making and complex system dynamics today. Yet, they are still used to predict future developments and to derive policy recommendations:

Through the 1990s, economic researchers typically started with a set of principles: for example, utility-maximizing by consumers and profit-maximizing for firms, far-sighted individual rationality, and a belief in equilibrium, which meant that structurally, individual's decisions in the models fit reasonably well together....By the late twentieth century, these principles formed the core of economists' vision of reality, in the sense that all economic models were built on these principles, or around variations of these principles like assumptions of bounded rationality or imperfect information (Beinhocker 2007: 460, citing Collander 1999).

According to all of these models, more production is always better and the price paid indicates the utility gained from consuming that production. The policy conclusions are easy: meeting the needs of current and future generations means ramping up productivity as much as we can. This has been the prime goal of policy and business conduct. Yet, upping the productivity of the fictitious commodity labor means changing the work life of humans. And often also ending the work life of humans. What happens to human needs in this process is, as we will see, not part of the models.

\subsubsection{What Is Utility and Where Is It Created?}

This section continues the search for an understanding of how human needs can be satisfied and unpacks the concept of utility and its consumption-based definition. Digging beneath the market-price indicator for utility (willingness to pay) we see something that psychologists have called the 'process benefits' or 'experienced utility' of the individuals involved in producing what can later be bought. It may well decline if the amount of what is done in one hour by one person is constantly ramped up. Or, in accounting terms, the amount paid for the same output falls. This is what productivity stands for in its conventional definition.

The goal of contemporary psychologists and the economic Nobel Prize-winner Daniel Kahneman has been to shed some empirical light on the pleasure and pain that people experience during their everyday activities. His surveys seek to capture 
the happiness of an individual over a period of time, e.g., while working. Experienced utility is defined "as the sum of the momentary utilities over that time period; that is, the temporal integral of momentary utility" (Kahneman/Krueger 2006: 5).

So, instead of measuring my utility and happiness solely through my shopping expenditures, these surveys seek to capture how much pleasure or pain I experience in every situation throughout the day. This sheds a very different light on notions of how we can support human need satisfaction but also requires a change to some of the basic models with which production processes are captured and analyzed.

This is the domain where ecological economics has anchored some of its most important alternative perspectives. Some of its leading thinkers, like Robert Costanza, Joshua Farley, Hermann Daly or Paul Ekins have juxtaposed wealth production functions in mainstream economics with those that capture people and planet and make them part of the economy. The following are my own synopses of slightly diverse versions in several publications (Ekins 1992: 147-155; Costanza et al. 1997: 273-275; Ekins 2000: 52-54). Figure 3.1 shows the production function of an economy as portrayed by mainstream economists.

We see that utility sits at the very end of the production process where consumption has resulted in profit for the producer and the pleasure of the buyer who has consumed the goods. Thus, an increase in consumption is identical to an increase in utility or need satisfaction. This model lacks information on both input and outputthe (scarce) means of production and the potentials for utility creation (the ends). This results in two limits to attention and creativity in thinking about economic development, which are highlighted by ecological economists who add some boxes and arrows to the graph (Fig. 3.2). In particular, they amend two categories: the

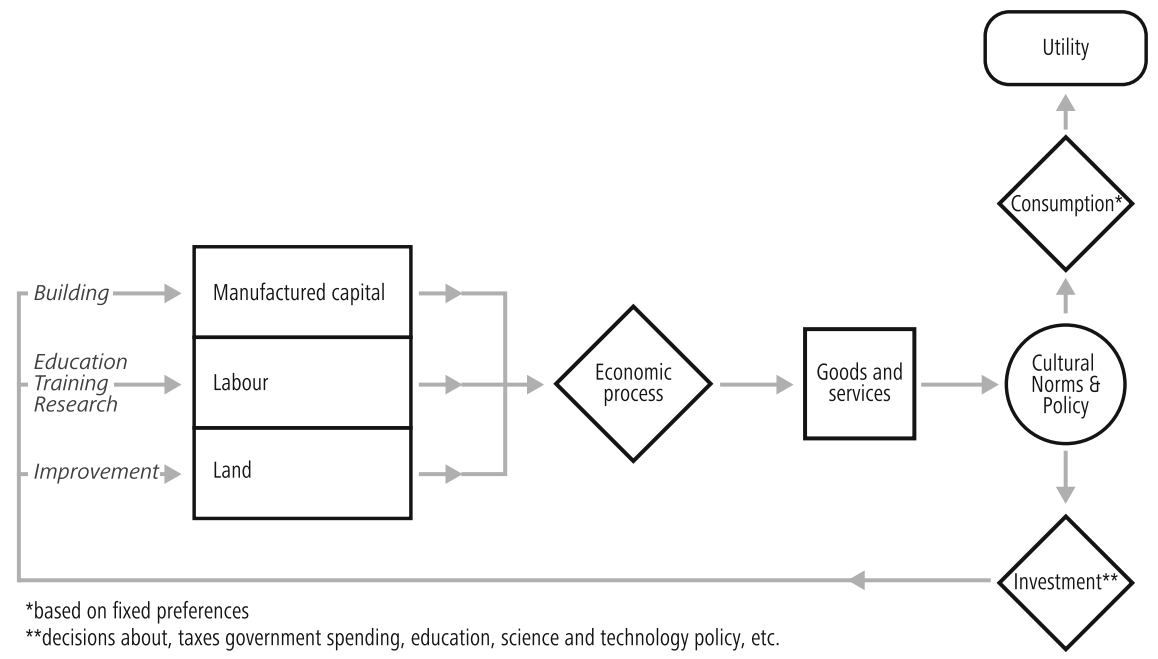

Fig. 3.1 Mainstream economics model of wealth and utility production. Source Based on Ekins (1992, 2000) and Costanza et al. (1997) 


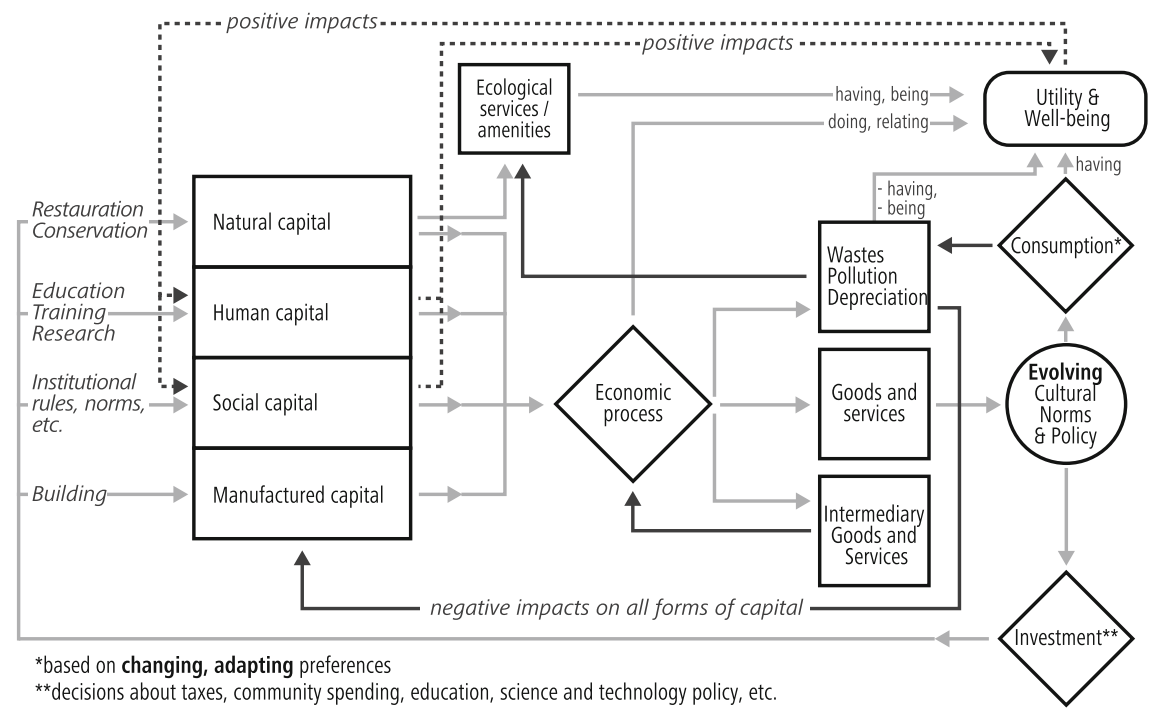

Fig. 3.2 A differentiated model of wealth and utility production. Source Own illustration based on Ekins $(1992,2000)$ and Costanza et al. (1997)

factors of production and the stages at which utility or disutility can be created during the process. The former introduced the now widely adopted four-fold concept of capital that will become relevant below when discussing how economists anticipate the future, whereas the latter is what I am interested in here: aspects of human existence that escape the category of product or service consumption.

- Land is now portrayed as environmental capital and its understanding is expanded by adding ecological services. These have a utility or well-being effect outside of economic processes through, for example, beauty and recreation in lush forests or meadows. The three economic roles are the provision of resources like minerals, grains, wood or stone; of direct ecosystem services like climatic regulation or fresh water; and supplying a sink to absorb waste, like composting organic waste into humus.

- So waste is included as an explicit category that economic processes and consumption create. It will affect utility (pleasure) directly if it stinks or pollutes the air, and it impacts the regenerative circuits in ecological systems services.

- The concept of labor has been transformed into human capital that includes not only the execution of production tasks but also the psychological, emotional and social skills around them such as motivation, knowledge, creativity and health. Also new is social capital, which embodies the relationships, norms, and procedures or institutions with which production is organized. Both are positively influenced not only by investments but also by the general level of utility and well-being on the side of the people involved - e.g., positive spirals of motivation, mutual support, a sense of accomplishment. This effect flows in both 
directions, as good social and human capital tends to lead to higher degrees of reported well-being and experienced utility.

- So utility is seen to have many sources, flowing from the entire production process as well as the quality of the consumption process of the product or service I paid for. Do I sit down on a bench in the sun or do I slurp my ice cream behind the steering wheel, rushing home to feed the kids? This process quality of utility is highlighted by the introduction of four modes of engagement which we will discuss in more detail below: The mode of being, e.g., the enjoyment of a high quality environment or the discomfort due to a high level of waste or pollution in the air. Also: does my job context make me feel challenged and supported in a meaningful way to develop my skills? The mode of having results primarily from consumption but also directly from the natural assets to one's availability. In the mode of doing it is important how the work process is set up and if I, for example, feel safe and in control, whereas the mode of relating or interacting captures all the social organizational structures, e.g., do we have enough breaks and can we talk to each other, or is the work process interactive (see Ekins 1992: 147-155).

- The last difference lies in the way in which cultural norms and policies impact consumption and investment preferences. Here, choices have the potential to evolve rather than be fixed. This quality of change goes beyond the changes in preference ordering that mainstream economics includes to, for example, capture me being fed up with cars and now liking bicycles: it might mean instead that individual choices and cultural norms shift toward not wanting to consume more because people feel they have enough (Costanza et al. 1997: 273-275).

This comparison makes three points that are very important for the sustainability agenda. First, how the mainstream economic view ignores any direct utility gains from intact nature as well as the often damaging effects that waste, as a result of production and consumption, has on the future quality of ecosystems. At some point we might get to mimicking nature's symbiotic relations, in which the waste of one process serves as the input factor of the next. Yet, such cradle-to-cradle designs remain the talk of the future, and in order to transform our production and consumption systems accordingly the models must provide the information we need.

Secondly, it highlights the fact that the mainstream cost-based input-output models of production say nothing about the pleasure-pain impact of participating in such guided production processes. Here we find the connection with the concept of experienced utility and the limitation of accounting for utility or happiness only in the role of consumers: most of us are also workers and spend much more time in this role than in the one of shoppers.

Thirdly, and relatedly, it shows the massive blind spots that a consumption-based model of utility generation brings to thinking about solutions for less resource-intensive need-satisfaction strategies. It says that we only thrive when we shop or eat or watch television, while working is an unfortunate necessity to generate the money we need for that. We have to trade the production factor labor for income so we can buy more happiness. 
Given that most people spend many more hours of most days working than consuming, this blind spot is huge. It also raises several questions that the differentiated model in Fig. 3.2 picks up on: Do humans not enjoy engaging in productive activities? Do we not all participate in providing and receiving services like cooking or dancing without pay? So why not emphasize need satisfaction during productive processes instead of sacrificing them to serve sacrosanct productivity goals? What have we gained if there are ever more goods and services to choose from but we have no time to really enjoy them anymore? Yes, willingness to pay for compensatory measures and convenient 'to-go' solutions might even increase, but does this really indicate overall better need satisfaction?

\subsubsection{Is 'Having' Really All the Fun There Is?}

Manfred Max-Neef developed a helpful tool to understand human needs that increases the creative imaginary space for sustainable innovations that target experienced utility and well-being. This popular Chilean development economist has called himself the "barefoot economist" after spending 12 years with the poorest communities in Latin America. His moment of revelation came when understanding that none of the mainstream market-based economic concepts were of any relevance to them. Much of his work has thus been built on proper empirical experience in non-marketized societies. It therefore provides some fascinating reflexive systemic insight into the effect that living with certain institutional setups has on the way actors see and experience the world.

In an interview with Democracy Now! Max-Neef explained that his return to immersing himself in experience rather than deducing theoretical models made him conclude that we need an entirely new language in order to understand better what people really need. According to him, mainstream economics has nothing to say in support of the poorest people in the world if strategies are supposed to emerge from local systems rather than disrupting them. If you live in poverty, behaving like the selfish, insatiable atomic accumulator of mainstream theory won't get you very far, says Max-Neef: "You cannot be an idiot if you want to survive; you need networks of cooperation and mutual aid." In those communities, he observed, competition and the promise of monetary gain are not required for people to demonstrate enormous creativity, innovation and willingness to collaborate (Max-Neef 2010).

To illustrate which fundamental human needs he observed instead, Max-Neef has developed a matrix whose key messages I summarized in Table 3.2. The matrix limits the number of existential human needs to approximately nine. He does not argue that the list of nine existential needs is definitive or set in stone, but he says he is confident that a change in those basic needs would at best occur at a very slow pace. Also, these needs should be understood as interrelated and without hierarchies, except for the need of subsistence or survival, which comes first (Max-Neef 1992: 204-205). Here Max-Neef differs from other need-satisfaction approaches, many of which place self-actualization at the top and social, as well as material 
Table 3.2 Max-Neef's matrix of fundamental human needs

\begin{tabular}{|c|c|c|c|c|}
\hline Human needs & Being & Having & Doing & Interacting \\
\hline Subsistence & $\begin{array}{l}\text { Physical health, } \\
\text { mental health, } \\
\text { equilibrium }\end{array}$ & $\begin{array}{l}\text { Food, shelter, } \\
\text { work }\end{array}$ & $\begin{array}{l}\text { Feed, } \\
\text { procreate, rest, } \\
\text { work }\end{array}$ & $\begin{array}{l}\text { Living } \\
\text { environment, } \\
\text { social setting }\end{array}$ \\
\hline Protection & $\begin{array}{l}\text { Care, adaptability, } \\
\text { autonomy, } \\
\text { solidarity }\end{array}$ & $\begin{array}{l}\text { Insurance systems, } \\
\text { savings, health } \\
\text { systems, rights, } \\
\text { family }\end{array}$ & $\begin{array}{l}\text { Co-operate, } \\
\text { prevent, plan, } \\
\text { cure, help }\end{array}$ & $\begin{array}{l}\text { Living space, } \\
\text { social } \\
\text { environment, } \\
\text { dwelling }\end{array}$ \\
\hline Affection & $\begin{array}{l}\text { Self-esteem, } \\
\text { tolerance, } \\
\text { generosity, } \\
\text { passion, } \\
\text { sensuality, sense } \\
\text { of humour }\end{array}$ & $\begin{array}{l}\text { Friendships, } \\
\text { family, } \\
\text { partnerships, } \\
\text { relationships with } \\
\text { nature }\end{array}$ & $\begin{array}{l}\text { Make love, } \\
\text { express } \\
\text { emotions, } \\
\text { share, take } \\
\text { care of, } \\
\text { cultivate, } \\
\text { appreciate }\end{array}$ & $\begin{array}{l}\text { Privacy, } \\
\text { intimacy, home, } \\
\text { spaces of } \\
\text { togetherness }\end{array}$ \\
\hline Understanding & $\begin{array}{l}\text { Critical } \\
\text { conscience, } \\
\text { receptiveness, } \\
\text { curiosity, } \\
\text { astonishment, } \\
\text { discipline, } \\
\text { rationality }\end{array}$ & $\begin{array}{l}\text { Literature, } \\
\text { teachers, method, } \\
\text { educational } \\
\text { policies, } \\
\text { communication } \\
\text { policies }\end{array}$ & $\begin{array}{l}\text { Investigate, } \\
\text { study, } \\
\text { experiment, } \\
\text { educate, } \\
\text { analyse, } \\
\text { meditate }\end{array}$ & $\begin{array}{l}\text { Settings of } \\
\text { formative } \\
\text { interaction, } \\
\text { schools, } \\
\text { universities, } \\
\text { communities, } \\
\text { family }\end{array}$ \\
\hline Participation & $\begin{array}{l}\text { Receptiveness, } \\
\text { willingness, } \\
\text { determination, } \\
\text { dedication, } \\
\text { respect, sense of } \\
\text { humour }\end{array}$ & $\begin{array}{l}\text { Rights, } \\
\text { responsibilities, } \\
\text { duties, privileges, } \\
\text { work }\end{array}$ & $\begin{array}{l}\text { Become } \\
\text { affiliated, } \\
\text { co-operate, } \\
\text { propose, share, } \\
\text { obey, interact }\end{array}$ & $\begin{array}{l}\text { Settings of } \\
\text { participative } \\
\text { interaction, } \\
\text { parties, } \\
\text { communities, } \\
\text { neighbourhoods }\end{array}$ \\
\hline Leisure & $\begin{array}{l}\text { Curiosity, } \\
\text { imagination, } \\
\text { recklessness, } \\
\text { tranquility, } \\
\text { sensuality }\end{array}$ & $\begin{array}{l}\text { Games, } \\
\text { spectacles, clubs, } \\
\text { parties, peace of } \\
\text { mind }\end{array}$ & $\begin{array}{l}\text { Dream, brood, } \\
\text { remember, } \\
\text { relax, have } \\
\text { fun, play }\end{array}$ & $\begin{array}{l}\text { Privacy, } \\
\text { intimacy, free } \\
\text { time, } \\
\text { surroundings, } \\
\text { landscapes } \\
\end{array}$ \\
\hline Creation & $\begin{array}{l}\text { Passion, } \\
\text { determination, } \\
\text { intuition, } \\
\text { imagination, } \\
\text { rationality, } \\
\text { inventiveness }\end{array}$ & $\begin{array}{l}\text { Abilities, skills, } \\
\text { method, work }\end{array}$ & $\begin{array}{l}\text { Work, invent, } \\
\text { build, design, } \\
\text { compose, } \\
\text { interpret }\end{array}$ & $\begin{array}{l}\text { Productive and } \\
\text { feedback } \\
\text { settings, } \\
\text { audiences, space } \\
\text { and time for } \\
\text { expression }\end{array}$ \\
\hline Identity & $\begin{array}{l}\text { Sense of } \\
\text { belonging, } \\
\text { consistency, } \\
\text { differentiation, } \\
\text { self-esteem, } \\
\text { assertiveness }\end{array}$ & $\begin{array}{l}\text { Symbols, habits, } \\
\text { customs, values, } \\
\text { norms, language, } \\
\text { religions, } \\
\text { reference groups, } \\
\text { sexuality, } \\
\text { historical memory, } \\
\text { work }\end{array}$ & $\begin{array}{l}\text { Commit } \\
\text { oneself, } \\
\text { integrate } \\
\text { oneself, get to } \\
\text { know oneself, } \\
\text { actualize } \\
\text { oneself }\end{array}$ & $\begin{array}{l}\text { Social rhythms, } \\
\text { everyday } \\
\text { settings, settings } \\
\text { which one } \\
\text { belongs to, } \\
\text { maturation stages }\end{array}$ \\
\hline
\end{tabular}


Table 3.2 (continued)

\begin{tabular}{l|l|l|l|l}
\hline Human needs & Being & Having & Doing & Interacting \\
\hline Freedom & $\begin{array}{l}\text { Assertiveness, } \\
\text { open-mindedness, } \\
\text { boldness, } \\
\text { rebelliousness, } \\
\text { tolerance }\end{array}$ & Equal rights & $\begin{array}{l}\text { Dissent, } \\
\text { choose, be } \\
\text { different from, } \\
\text { run risks, } \\
\text { commit }\end{array}$ & $\begin{array}{l}\text { Temporal/spatial } \\
\text { plasticity }\end{array}$ \\
\hline
\end{tabular}

Source Excerpt from Max-Neef (1992: 206-207)

needs, at the bottom. The assumption is that physical and social needs require fulfillment before more transcendent ones can be realized. Max-Neef rejects such a hierarchical ordering and says that even if people go hungry every day, their lives can still host relationships of dignity, creative moments of productivity and the feeling of connection with others (Max-Neef 1992: 204-205).

The column of being lists personal or collective attributes; having registers institutions, norms, mechanisms, laws or tools in the material sense; doing relates to personal or collective actions; and the final column of interacting lists locations and milieus as defined in time and space. Max-Neef explains that this last existential category is much better captured in the German term 'befinden' or the Spanish 'estar,' as they combine a space with a state of being (ibid. 1992: 207).

What the matrix highlights is that having is only one way of satisfying existential needs and that products like food or shelter are not a need as such, but instead a satisfier of the need of subsistence. All products are thus viewed in relation to the satisfying strategy they fulfill. The desirability of economic goods like, in his example, books, laboratory instruments, tools, or computers, only comes from the role they play in strategies of satisfying needs. They are vehicles in actualizing the need for understanding through the satisfying strategies of investigating, studying, experimenting, educating, etc., that he grouped in the column doing. Here, products become the deduced variable and culture, context and resources determine which are most suitable — or sustainable. It also means that widespread individual book ownership or the simple presence of many books with high prices does not equate to better need satisfaction - an equation that mainstream economics would make. On the contrary, the process of understanding is often less painful or much more pleasurable if you have a peer group with which to discuss things or a parent reading out loud to you.

So according to Max-Neef, "a satisfier is in an ultimate sense the way in which a need is expressed," while "goods are in a strict sense the means by which individuals will empower the satisfiers to meet their needs" (Max-Neef 1992: 202). Also, one satisfier can actualize different needs at different times and several needs at the same time, depending on how the process of creating goods or consuming them is organized. Mainstream economics lacks such differentiations. Here, commodities bring utility through their consumption, as the willingness to pay for them indicates. The amount of utility generated can be measured and compared to other sources through the indicator of price. So the utility of books, for example, pops up only in moments when they are sold (again). 
In the matrix, even the mode of having includes many elements that are very difficult to quantify and monetize, like human rights, insurance systems, and educational policies. Mainstream economics tries to use willingness-to-pay surveys to judge their importance to people. People might be asked how much in monetary terms a public health insurance system should cost per capita. But a simple twist in the question will change the answer: asking whether they have to pay to keep something renders different results from asking how much they would want to be paid as compensation for it being taken away. So just checking the price will not get you far in understanding the complete picture of how and why certain choices are being made or which needs exactly are satisfied through it.

This is also one of the conclusions of Well-Being for Public Policy by world-leading well-being psychologists Ed Diener and John Helliwell. It compiles the research of many psychological studies on the relationship between willingness to pay, income and the well-being that people report in surveys to conclude that "the economic decisions that people make, and the money that they have, may not be perfect indicators of the well-being that they experience" (Diener et al. 2009: 40).

The most important message of Max-Neef's matrix in terms of a Great Mindshift, however, lies even beyond exposing blind spots of monetization and price indicators. It declares the set of human needs to be limited and the range of possible satisfiers to be abundant once the economistic consumption lens is removed. This is in direct contrast to the standard economic assumption of unlimited human needs and scarce resources, and it opens up a plethora of possible solutions for good lives which do not have to cost the Earth. The satisfiers listed in Table 3.2 provide only a few examples. Consequently, the goal of development can become a holistic and endlessly creative endeavor of keeping environmental and human relations responsive to an unfolding of satisfying potentials, so that material goods serve satisfier strategies in alignment with contextually specific circumstances.

The mainstream model, on the other hand, makes material goods the ends in and of themselves and assumes that all need-satisfying springs from them. This means that successful development can only be imagined as linear in one direction: more gain. Slowing down and reducing production cannot be a strategy because then well-being will drop. According to Max-Neef, adopting this worldview means that "the speed of production and the diversification of objects have become ends in themselves and as such are no longer able to satisfy any need whatsoever. People have grown more dependent on this system of production but, at the same time, more alienated from it" (Max-Neef 1992: 204).

Max-Neef therefore criticizes prevailing development policies, which are primarily aimed at increasing consumption possibilities by market integration. They stimulate the accumulation of goods regardless of human development status in those systems. This results in an increasing dependence on externally generated satisfiers, whose control lies beyond the influence of poor communities.

One example of this has been the structural adjustment programs of the International Monetary Fund in the 1980s, in which many poor countries had to embark on export-driven development strategies. This means the focus lay on the 
comparative advantage of a few goods whose production was ramped up for international competition. It sometimes meant that entire economies became dependent on the world market price of one or two products. This had some cataclysmic effects. The fates of Ethiopia, Burundi, and Uganda when the world price of coffee fell in 2001 are prime examples (Francis/Francis 2011). It also meant that the diversity of what was harvested at home was reduced significantly, leading to a simultaneous dependence on world market prices for imports. This type of double dependency becomes especially problematic when world prices are affected not simply by actual supply and demand changes but, as price hikes of up to $200 \%$ for some grains showed in 2006-2008, food is also susceptible to financial speculation.

In addition, as the UN Conference on Trade and Development (UNCTAD) points out in its 2013 Trade and Development Report, producing for the world market means that every cent in wages is a cost to be avoided. Production for domestic markets, on the other hand, means that higher wages mean more purchasing power on the demand side. From a macroeconomic perspective this benefits everyone because price elasticity goes up. UNCTAD points out that statistics from almost all export-driven countries demonstrate how real wages in the export sectors have not increased with productivity gains over the last two decades. Coupling this with slow growth and demand on a global scale leads the authors of the report to conclude that "export-driven development is no longer viable" and that "economies will perform better with more balanced strategies" aimed at "balanced growth" and "a greater role of domestic demand" (UNCTAD 2013).

Long before these empirical numbers were gathered, Max-Neef had been arguing that human need-satisfaction strategies should emerge from each individual context, respectful of social practices, forms of organization, political models and values as well as the natural systems in which they are embedded. This may lead to less rapid increases in economic output as measured in GDP, but ensures a more balanced and therefore resilient change process controlled by the people it affects. Once the need for subsistence is no longer threatened, it may well deliver more happiness than running after GDP per capita jumps.

\subsubsection{Checking Human Happiness and the Link with Income}

The scholars cited at the beginning of this chapter second Polanyi in his assessment that making endless gain or growth the polestar of societal aspiration might have been the most transformational idea of the Enlightenment movement. It overarches the third prime idea in mainstream economics: the pursuit of greater happiness or utility (need satisfaction) is best done through more consumption. While the subchapters above have shown the limiting blind spots of these reductionist models of 
where and how utility can be generated, this one is going to scrutinize the idea that more is always better.

In mainstream economics more income always means better lives, as expressed, for example, in the important indicator of GDP per capita in poverty and welfare statistics. Yet, the fallacy of conflating income levels with need satisfaction and well-being can be exposed by crunching the numbers. Researchers have discovered that the level of reported well-being and happiness (which, in economics jargon, is called 'perceived utility status'), stops being causally linked to GDP growth once a certain level of income per capita is reached. This observation is called the Easterlin Paradox after Richard Easterlin, the American economist who pioneered research in this field in the 1970s.

The most striking example of decoupling rising GDP and per capita income from perceived quality of life was revealed in the results of a Gallup poll in China. Some 15,000 people were interviewed between 1994 and 2005 and the researchers found that average life satisfaction had gone down despite a rise in real incomes of $250 \%$ (Kahneman/Krueger 2006: 16).

There has been heated debate over this issue and the quality of data in some of the measurements over time (time series). However, the first World Happiness Report (2013) issued by some of the world's leading happiness and well-being researchers - John Helliwell, Richard Layard and Jeffrey Sachs - collates a lot of data from diverse sources and shows that the Easterlin Paradox is not so paradoxical after all. Once the standard economic assumption that more income naturally means more happiness is turned into an empirical research question, one comes to find this leveling off rather logical. The following presents some research results that support this mindshift.

It was qualitative empirical meta-research conducted on subjective well-being research that delivered most of the answers that solved the paradox. These affective theories of well-being have experienced a renaissance since the 1960s. Before that, modern post-Enlightenment science and the rise of behaviorism approaches in psychology in the 1930s had excluded many of these approaches and insights from consideration as 'valid evidence.' Instead, behaviorism fits well with the goals of economics as defined by Robbins, explaining choice-making without understanding people's deeper motivations in detail. This period also marked an important turning point when income began to be seen as an important indicator of well-being. The birth of GDP in the 1940s complemented the turning with a macroeconomic indicator.

The scientific study of subjective human well-being only gradually re-emerged in the 1960s and it took what was called an 'affective revolution' in the 1980s to reinstall it firmly on the horizon of the social sciences - while economics remained slow on the uptake (Diener et al. 2009: 15-16).

This revolution was about asking people how they felt. The 'objective' conditions such as income, unemployment, and sanitary provision may be captured in order to understand context but are not elevated to the status of indicators for utility levels. In an overview article, Daniel Kahneman and his colleague Alan Krueger argue, "that it is fruitful to distinguish among different conceptions of utility rather than presume to measure a single, unifying concept that motivates all human 
choices and registers all relevant feelings and experiences" (Kahneman/Krueger 2006: 4). Their empirical findings support the amended production model (Fig. 3.2) and the Max-Neef matrix (Table 3.2) in many ways. Most important for subjective well-being are the quality of social relationships, the relative notion of income or wealth and how sociocultural environments impact on people's aspirations and values.

So while these researchers also seek to understand how to maximize happiness or utility, they make the effort of actually asking people what makes them feel good. They investigate its sources empirically rather than simply saying that it will come and grow with consumption. Also, Diener and Helliwell point out that many things, like love, social relationships, environmental pollution, fair and effective governance and virtue and spirituality all play important roles in people's experienced well-being, but are difficult if not impossible to measure through willingness-to-pay estimates (Diener et al. 2009: 37). They also observe that quite often, individual predictions of what will make for happiness go wrong.

So while most metrics and success benchmarks for progress and development involve constantly upping per capita income, when asked, people tend to claim that health, recognition and a meaningful engagement lie at the center of what makes their lives satisfying. Chronic pain and unemployment are amongst the worst things that can happen, in particular in societies where those not finding a job are viewed as lazy benefit-seekers or live with no social support and much reduced social contact.

The influence of social norms on what we believe - or at least say we believecreates well-being has also been well documented. When comparing ratings on work and childcare in surveys in which the respondents talked to a real person with those where they anonymously press buttons on an app, the former type of survey reveals higher rankings for childcare. According to Kahneman and Krueger they are "likely to be reminded that both work and childcare are desirable aspects of their life. Reports of how much they enjoy these activities will tend to be anchored in that general assessment, resulting in a favorable bias. Respondents may also feel some social pressure to tell interviewers that these domains of life are enjoyable" (Kahneman/Krueger 2006: 13).

App technology, however, has now made it easy for people to report their feelings during the day, while engaged in different activities. Grouped into three positive categories (happy, warm, enjoying myself) and six negative ones (frustrated, depressed, hassled, angry, worried or criticized) individuals can select their current state from zero (not at all) to six (very much). In this way answers are much more immediate, and do not allow for time to reflect on the wider social context.

The results, say Kahneman and Krueger, indicate that net affect, also called "mood score," from these ratings "is highest, on average, when individuals are engaged in leisure activities (such as socializing after work) and lowest when they are engaged in market work and investment or personal maintenance activities (such as house cleaning)" (Kahneman/Krueger 2006: 12). The morning commute is viewed as particularly negative - unless it is undertaken in the company of others, which again hints at the importance of social contact. 
What do these findings tell us about human needs, decision-making motivations and the importance of a constantly growing number of possessions? They indicate that Easterlin had not so much discovered a paradox as a natural development process. This is indeed what Martin E.P. Seligman, another renowned positive psychologist, seems to conclude in an overview article on well-being studies: economic indicators are extremely useful in analyzing societies in their early stages when the fulfillment of basic material needs is important but "as societies grow wealthy, however, differences in well-being are less frequently due to income, and are more frequently due to factors such as social relationships and enjoyment at work" (Diener/Seligman 2004: 1).

None of this provides much support for any law-like equation of more economic output with more happiness for everyone. If societies are built around this equation, it results in pathways of development and civilizations that psychologists have diagnosed as resembling a 'hedonic treadmill.'

In the 1970s researchers started investigating the relatively small and short-lived effects caused by changes in people's circumstances. They observed people who had suffered lasting setbacks to their health or had been afflicted with disabilities. The results showed that within two years most had returned to the average life satisfaction they had reported before their misfortune. Only those with severe disabilities did not fully recover.

The same leveling out holds true in the case of important positive events like marriage. Reported well-being typically increases one year before and after the actual event before returning to the mean. Purely economic gains like a salary increase or buying and enjoying a new car show the same adaptation effects but the return to the norm is much faster (Kahneman/Krueger 2006: 14).

In the 1990s, Michael Eysenck, a British psychologist, formulated the hedonic treadmill analogy as a generalization of these findings: the more you have, the more your expectations rise and the more things you want. So it is not so much the absolute number of possessions that matters but the relative amount of what we have and against which we judge changes (Eysenck 1990). So even with a high income, instead of being happy with what you have, you think that having more will make you happier. This is especially true when your society promotes ever more possibilities of consumption and richer lifestyles. One great example of this is the income levels deemed necessary for having a good life in the United States. The median estimate of Americans as to how much income they felt they needed to "fulfill all of [their] dreams" was approximately $\$ 50,000$ in 1987 and rose to $\$ 90,000$ by 1996 - in constant dollars (Bok 2010: 13).

Other impressive survey results with the same message were cited by Stephen Marglin, a Harvard economist in The Dismal Science: How Thinking Like an Economist Undermines Community (2010). He refers to a 2005 PNC Bank survey of wealthy individuals.

When asked how much they needed to feel financially secure in the future, respondents consistently cited a need to approximately double their current level of assets. Those with $\$ 10$ million or more felt they needed a median of $\$ 18.1$ million; those with $\$ 5$ million or 
more needed \$10.4 million, and those with a half million to \$1 million said they needed \$2.4 million (Marglin 2010: 200, citing PNC Advisors 2005).

So first and foremost, people's ideas about what they need increase in line with what they have. Here, financial security represents people's perception of being able to continue living the life they know. So, just taking numbers into consideration does not tell you much about what people need in order to feel that their lives are rich. Only if we contextualize survey data in the socioeconomic environment can we start understanding the specific connections between income and well-being. If, for example, former citizen entitlements like public health care, education, pension schemes, etc., are increasingly turned into commodities sold in the market, your access guarantee starts depending on your private wealth. Thus, the more monetized and privatized a society's relationships, the more central income will be to people's sense of security and the quality of goods and services that they can afford. It does not necessarily mean that they also feel happy, however.

The role of reliable income in feeling secure is confirmed in many studies in richer societies that find secure income ranks higher than a growing absolute amount. They also support the need to contextualize: connecting income level with other losses, like a blow to health, for example, has shown that people with higher incomes suffer a less dramatic drop in life satisfaction (Kahneman/Krueger 2006: 14). And in all societies the wealthier strata are on average happier than the poor.

As long as societies hold money to be the single most powerful access mechanism to experienced utility or need-satisfaction strategies, income will be very important; but only as long as I can buy much more treatment and services to alleviate my disabilities than I could get without private pay. Max-Neef has taught us to understand the relationship between physical goods and artifacts like money and the role they play in allowing for a need-satisfaction process to emerge. Without such processes they are rather useless things.

So the use of qualitative findings to capture the relationships within a given system in a holistic way gives rise to much better insights into the property and role that individual elements play within it. Reflexive sciences would insist that the characteristics of individual elements cannot be fully captured without checking for the relationships in which they are embedded. In his 2010 meta-study on happiness research and its relevance for policy, Derek Bok, former Harvard University president, offers a rather anecdotal account of the relational benefits that being rich brings to people: "Their jobs tend to be more interesting, they have more control over how they spend their time, and they are more likely to give orders than to receive them. The mere fact that they have succeeded in what they set out to achieve should make them more satisfied with their lives" (Bok 2010: 15). Here we find a lot of pointers for satisfiers in the category of doing, being and relating, that could be served with qualitative rather than quantitative changes in economic processes like work. Max-Neef's barefoot economist findings in poor communities are seconded by data from rich societies: the range of possible satisfiers is far wider than what markets offer. 
Researchers concluded that it is attention that plays a crucial role for the quality and intensity of an experience and that individual attention is high when something is new. With time, however, the fraction of attention concentrated on the new thing goes down and so does its influence on one's general state of well-being. Working with attention lies at the heart of mindfulness practices and therapeutic strategies deployed to cure the increasing number of people that burn out in hedonic treadmill civilizations.

Constantly keeping attention on what ubiquitous advertising is suggesting one lacks in one's life and what others have that is better is not a good recipe for happiness. Neurosciences show that mental activity creates neuronal structures and, depending on which skills people use most or what they pay attention to regularly, some wirings and associations of their brain become more connected. Some parts even grow physically bigger. So if societies create attention architectures that keep people concentrated on accumulation and monetary expressions of value, this influences their ideas about a good life, the best need-satisfaction strategies and, ultimately, their experienced happiness (Hanson 2009: 18). Neurosciences and biochemical research also tell us that a brain processing massive excitement would fry if it did this over longer periods of time. Accumulating limitless stacks of happiness is thus neither possible nor desirable. Happiness is a flow phenomenon rather than a stock that can be hoarded. Its measurement takes place on a scale between high and low and its levels are expected to fluctuate. It is not measured with aggregated growth curves.

Psychologists like Tim Kasser provide more scientific evidence against the conflation of more gain with more happiness, and also against the 'law' that all humans are naturally wired toward competitive accumulation. He shows how experienced well-being of even materially wealthy lives seems to decrease if too much attention is given to economic indicators and the satisfier strategies of having.

\subsubsection{How Does a Homo Economicus Feel and Act?}

The technical term for what has become the 'representative agent' in mainstream economic models is 'Homo economicus.' Its character is the embodiment of the first law of the human condition: constantly seeking to improve the hedonic calculus and constantly comparing and competing with others over scarce resources and best offers. The cost-benefit analyses that this agent undertakes lie at the heart of explaining human behavior and the choices that should be expected. The financial crisis has shown how helpful the resulting predictions are for complex real world dynamics. But this is not the topic at hand. We want to stay with the assessment of how key ideas and concepts of the mainstream economic paradigm not only limit which development solutions are imaginable and justifiable but also how their incorporation in culture and institutions drives societies away from sustainable outcomes. 
The latter is the theme of US psychologist Tim Kasser's High Price of Materialism. It collates ten years of psychological research that shows why we should speak of the 'Easterlin Logic' rather than 'paradox.' Kasser provides rich sociological evidence on the other claim that the choice of particular satisfiers impacts psychological and social development and thus future-need perception and well-being. He does so by investigating how materialistic values relate to well-being. The questions he seeks to answer are the following: "What happens to our well-being when our desires and goals to attain wealth and accumulate possessions become prominent? What happens to our internal experience and interpersonal relationship when we adopt the messages of consumer culture as personal beliefs? What happens to the quality of our lives when we value materialism?" (Kasser 2002: 4)

Values research is an important strand of psychology and in itself shows that not all humans are materialistically wired. Box 3.1 provides a brief overview of how in some research designs values have become an explicit component, next to questions of epistemology, ontology and methodology.

Box 3.1 Values research - axiological aspects of scientific paradigms

Psychologists have found a relatively high commonality of basic value orientation varieties across cultures and age groups and have grouped them into ten meta-categories that subsume several single value statements and aspirations or goals for life to which people holding these values would ascribe. In all cultures one finds the following: universalism, benevolence, tradition, conformity, security, power, achievement, hedonism, stimulation, and self-direction.

Individuals and cultures show different value sets with typical patterns of correlation and non-correlation between some of these meta-categories. It is unlikely, for example, that people with a high score in universalism will also have a high score in power, whereas benevolence and self-direction will typically rank highly together. These settings influence people's aspirations, judgments and behavior in a given context and the categories are applied when seeking to understand differences in decision-making and support of certain political or economic ideas and proposals. Approaches like that of the Global Scenario Group presented here, base their stories for potential developments on the assessments of sets of values and how these might influence the decisions people take, in, for example, policies and consumption.

For a wider discussion and a map of the typical category correlations and single values within them, see the Common Cause Handbook of the British Public Interest Research Centre (PIRC). It also includes instructions on how to work with value change for improved well-being and sustainability. 
For his own research questions, Kasser selected people who put making money and having possessions relatively high on their overall list of things they deemed important. In order to find this group, surveys were conducted with an 'Aspiration Index' that listed a variety of goals which participants ranked according to their importance. If someone ranked, for example, financial success higher in comparison to other goals like a good family life and friendships, it indicated a materialistic value set on the index.

Each life goal was associated with descriptions of aspirations that have been observed to relate to particular values like benevolence, self-direction, security, power or hedonism. In the category of financial success, for example, these included "you will be your own boss," "you will have a job with high social status," "you will have a job that pays well," or "you will buy things just because you want them."

The study also documented aspirations in non-monetary goal categories like 'image' and 'fame' that competitive societies tend to treat with similar importance. The commonality between these three goals is that they are extrinsic motivations, which means they involve seeking a sense of worth outside oneself. Feeling worthy thus depends on external rewards and the praise of others.

From a methodological point of view we can see how Kasser tested how people who most closely resembled Homo economicus felt and how they experienced life. The complete survey also had four questionnaires to assess the individual's score on two important well-being characteristics (self-actualization and vitality) and on the two most common psychological disorders (depression and anxiety). The results showed that people whose values were centered on the accumulation of wealth, material possessions, or fame, faced a greater risk of unhappiness, including anxiety, depression, low self-esteem, and problems with intimacy, regardless of age, income, or culture. Kasser repeated the study several times with different groups and compared his findings with those of others. He added more extrinsic orientation values like narcissism and used a more open methodology in which goals were not assigned by providing pre-set aspirations but defined by the individuals themselves. Across the board he found the same picture emerging: "The more materialistic values are at the center of our lives, the more our quality of life is diminished" (Kasser 2002: 14).

Another group of researchers has found evidence that many who care a lot about making money and succeed can offset the loss of well-being they experience by sacrificing aspects of their life like family or leisure time. Overall, however, Kasser's finding are supported, as Bok concludes in his meta-study, because "the findings of psychologists convey a warning that being preoccupied with getting rich carries a substantial risk of leaving one unhappy and disappointed in the end" (Bok 2010: 15).

The blurb accompanying Thrive, the 2014 bestseller by Arianna Huffington, puts it this way: "Our relentless pursuit of the two traditional metrics of success-money and power-has led to an epidemic of burnout and stress-related illnesses, and an erosion in the quality of our relationships, family life, and, ironically, our careers." So, encouraging and training people to see and think like a Homo economicus 
seems like doubtful advice from a life coach and a terrible flaw in the discipline of mainstream economics.

Kasser, however, went beyond individual happiness and also addressed the question of what exactly social processes and institutions created with a Homo economicus in mind do to the development of society. The results show that materialistic people are possessive in the sense that they prefer to own and keep things rather than borrow and rent, are less generous or more unwilling to share their possessions, and envious of other people's wealth. They also feel unhappy when others have things they want.

Furthermore-and highly relevant to sustainability strategies-materialistic values and pro-social values operate like a seesaw: people with high extrinsic value sets are likely to show lower levels of intrinsic values like self-realization, psychological growth or contributions to society that involve empathy for others or concern for the environment (Kasser 2002: 18-19). Thus, materialistic values not only reduce individual well-being and perpetuate feelings of insecurity and being constrained, but they also hamper relationships with other people and the natural environment. This effect is particularly strong when people have money on their mind during decision-making.

Psychologists like James Heyman and Dan Ariely from Harvard University, for example, demonstrated the difference between money markets in which financial compensation motivates action or effort, and social markets with no rewards, gifts or other tokens. In three experiments they show that using "monetary payments causes participants to invoke monetary-marketplace frames and norms" whereas people are actually willing to expend more effort in exchange for no payment (Heyman and Ariely 2004: 787).

Unlike mainstream economists, they use relational theory that distinguishes four basic types of social relationships, of which only one is 'market pricing,' in which cost-benefit calculations dominate. The others are 'communal sharing' with a dominant culture of 'we-ness'; 'authority ranking,' which avoids the question of who is ordering whom about and who is delivering; and 'equality matching,' in which everyone gets the same rewards and reciprocity is monitored.

Heyman and Ariely found that, as long as people are not explicitly told that they are paid, they consider themselves to be in one of the three non-money market settings and their outlook on what they should do is different. Experiments with students show that not offering a payment often results in greater efforts than when money is proffered, especially when it concerns tasks like 'helping out' such as carrying a sofa upstairs. When money is offered, cost-benefit thinking is used as people seek to match their effort to the rate of pay. High pay means more effort in solving simple tasks but low or even medium rates of pay mean less effort than no pay. Experiment results suggest that monetary incentives can have significant effects on how tasks are framed and therefore the motivation with which we engage in them. When no payment is mentioned, or when it is offered in the form of gifts, effort seems to stem from altruistic motives and the exchange is viewed as a social one (Heyman/Ariely 2004: 792). 
Yet, the marketized and commodified way we live today makes cost-benefit thinking almost unavoidable. Diener et al. tentatively hint that societies could feel very different if economic indicators were not constantly present, but instead replaced with information on how many spent time with their family, did a good turn for their neighbor, exercised or engaged in meditation and prayer (Diener et al. 2009: 40).

In Sect. 3.3 I will discuss the role of price signals as guiding indicators in more detail. Here I want to conclude with a summary of what psychology, sociology and neurosciences tell us about the genesis, power and changeability of mental path dependencies. It shows that the methodological stunt of making Homo economicus the representative agent for all of humanity is scientifically false. In the light of this fact, merely containing criticism by tinkering around the edges is insufficient. The sociologist Welzer ridicules the way that mainstream models have started to tinker by, for example, varying exogenous preferences: some green values are brought in but the main impetus of wanting more remains the constant hypothesis of the theory from which everything is deduced. Would I now rather have two funky bikes instead of one car? In this paradigm, people's core motivations cannot change. Yet, historical studies show they can. The concept of psychogenesis, for example, encompasses changes in endogenous preferences (do I really want to have all this stuff?). This is simply excluded from mainstream economic frameworks even though sociology suggests no less than that "changes in social structure lead to the emergence of new social forms and practices, and thus to psychologically different people with different needs" (Welzer 2011: 15).

\subsubsection{Summary: Human Need Perception and Well-Being Depend on the Processes Behind Creating Wealth}

The research I have presented above renders obsolete the mainstream concepts summarized in Table 3.1 and used to understand human needs and their satisfaction. Human needs are not endless (although maybe the 'wants' created by advertising are) and utility or happiness are much more than fleeting sensations of joy and excitement experienced after consuming new things. After securing material needs for subsistence, the most important factors for happiness and well-being are not the absolute amount of income but income security. The other important aspect is the match between income or available money and the costs of having access to the need-satisfaction strategies one deems necessary for well-being. This quantitative ratio depends on the context in which the person happens to live and is usually corrected for by purchasing power estimates. These do not capture qualitative differences between offers of similar services, like public versus private health care or education. The bigger the qualitative gaps the less well people feel if they cannot afford access to private services. Also, the more explicit consumerist culture is advertised and declared to be normal, the more important 
conspicuous consumption becomes - and the money needed to participate in it. Anecdotal evidence in Germany has it that richer people drive Porsche but buy their groceries at the cheapest discount stores. So once we dig deeper, we find that happiness is an existential feeling of being on top of one's life and its challenges. Neither the utility of a product nor the happiness of a person can be measured by the price people are willing to pay for something. Yet, constantly calculating costs and benefits and guiding one's life by comparing numbers as expressions of value makes people lose their senses of worthiness, connection and caring.

So why should we continue to build societal development paths around the idea that constant accumulation is always beneficial to people or society as a whole? Well-being research helps bring to light the underlying needs that market-based consumption is actually serving and how many different options a society has to satisfy them. By debunking the consumption-happiness-maximization law we can thus become creative in finding solutions for improved utility that align with Earth's ecosystems and other people's needs for social relations, meaningful engagement and respect. It becomes possible to imagine reduced production and consumption levels without panicky reactions or unfounded excuses that doing so would necessarily decrease happiness, well-being and freedom.

This requires and enables system innovation processes that focus on unlocking political, economic and sociocultural path dependencies that were created to serve the stark utopia of endless gain through a market system. Thinking back to Fig. 2.5 on the materiality of ideas, we can see that creating processes with such vision and beliefs in mind resulted in a system that had the growth imperative wired into its functioning. This is of course the second part of Jackson's Growth Dilemma: that any 'degrowth' undertaken today - given current institutional setups-is unstable and causes unemployment and recession. I would add the breakdown of the financial markets. Without a doubt, instant degrowth would diminish the happiness of many. But it is the result of a structural crisis and not of the violation of some natural laws of human existence. Twenty-first century empirical research shows that those do not exist.

In this the qualitative survey data of well-being research and the historical observations of figurative sociology receive supporting evidence from natural sciences. Brain researchers have observed how our experiences of the external world and our judgments of them find expression in the development of our neuronal architecture. So quite literally, external circumstances, in their appearances as social, cultural, technological and economic institutions, design our internal infrastructure. These wirings determine how we experience and judge events now and in the future.

"What happens in your mind changes your brain, both temporarily and in lasting ways; neurons that fire together wire together. And what happens in your brain changes your mind, since the brain and mind are a single, integrated system" write Rick Hanson and Richard Mendius, cofounders of the Wellspring Institute for Neuroscience and Contemplative Wisdom (Hanson 2009: 18). And the brain changes through training just as muscles do. Hanson and Mendius quote Francisco Varela, the famous Chilean biologist and neuroscientist, when describing this 
mutually reinforcing relationship: "In the largest sense, your mind is made by your brain, body, natural world, and human culture - as well as by the mind itself" (Hanson 2009: 7).

These findings resonate with Welzer's 'mental infrastructures' that have path dependency effects embedded beneath cognitive processes of knowing or social fears of losing status or access. Referring to the economic growth paradigm, Welzer discusses how deeply rooted resistance to change can therefore be. Debunking it would play on people's fundamental "secret fears" that "everything they have established, everything they worked for, planned and believed in, could have been meaningless. The dimensions of meaning and identity that Western-style capitalist societies provide stand and fall with the functioning of the market" (Welzer 2011: 29).

So of course post-growth imaginaries and narratives may not necessarily gain traction right away. They may offer the least enticements to those who risk losing quite a few of their privileges if the promise of always more for everyone cedes and paradigms and narratives on fair shares become dominant.

I am not sure if this was the upset of the human self-image that the Brundtland Report foresaw to be necessary for sustainability to succeed. But surely, scientific concepts and models should help to understand and explain such an upset and its consequences instead of ruling it out by imposing theoretical iron cages.

The evidence behind policymaking would then look very different as well. Richard Layard, leading British happiness economist, argues that well-being research findings require turning mainstream concepts of productivity and competitiveness on their head. Given the hedonic treadmill and high price of materialism, he demands that policy should constrain the ability of individuals to earn and work much more than other people:

If a person works harder and earns more, he may himself gain by increasing his income compared with other people. But the other people lose because their income now falls relative to his. He does not care that he is polluting other people in this way, so we must provide him with an incentive to do so (Layard 2005: 229).

The proposed incentive is significantly higher taxation on working too much given that a true benefit to society as a whole can no longer be identified. Whether or not one likes this particular proposal, the important idea is that the adoption of a historically sensitive mind-set does not lend itself to there-is-no-alternative claims. Sociocultural circumstances and politico-economic institutions like markets shape people's mind-sets and imaginary and therefore their aspirations and preferred need-satisfaction strategies. In the light of their surveys, for example, Kahneman and Krueger suggest shifting attention from increasing consumption opportunities to an emphasis on increasing social contacts; shifting the emphasis from income for well-being toward a person's relative embedding in society; making possible a different allocation of time that reduces the amount of time people spend doing things they find unpleasant (Kahneman/Krueger 2006: 18).

Given that work in its current forms ranks high among those things in life which many say they do not like doing, some interesting strategies for sustainability emerge. A popular one is to reduce working hours, because this would allow for the 
wider sharing of paid work available, thus reducing unemployment-which is even worse for health and well-being. This said, one also wants to include an analysis of if or how this reduces pay and what it does to purchasing power and thus access in deeply marketized societies. In Great Britain, for example, where private debt is the highest in Europe and many low-paid workers have mortgages to service, the prospect of earning less in exchange for having more time does not mean an improved life. Unlocking path dependencies in complex settings require whole system change strategies with policy-packages hedging such detrimental side-effects.

Another approach could be to change the experienced utility itself, so that spending time at work was less of a nuisance. For this to happen, the idea of what makes a firm competitive would need to change. Its prime benchmarking purpose would become delivering high product and process utility in the most resource-light and resilient way - instead of myopic and narrow price competitiveness. It would include outcomes of social capital (good relationships, reported well-being, and trust), human capital (giving people skills, their ability to creatively innovate and collaborate), and the protection of environmental capital (as little resource use as possible for the delivery of certain need satisfiers). Some corporate strategies do involve such ideas, but usually not as the goals of their system: they are means to better deliver on the unchanged goal of maximum profit.

To level the benchmarking playing field for those companies that sincerely try to turn these means into goals, regulatory changes are necessary. These goals could also free corporations from the pilot paralysis they report regarding their sustainability endeavors. This would, however, require changing their business model and thus corporate charters themselves. Other measures like taxation or subsidies are of course political incentives that still induce people to work harder. In a transformational agenda the holy cow of constantly striving for labor productivity increases should have to justify its merit: "if tax-cutters think people should work still harder, they need to explain why" (Layard 2005: 228).

Today's standard measures and indicators emerged from the ideas about the world held by their inventors. Stripped of this context they function like 'objective' reference frameworks in arguing how to do things adequately. So if our culture, signals and symbols were transformative in a way that steered clear of materialistic values, extrinsic incentives and monetized expressions of worth, the perceived need for ever more gain or new stuff in materially saturated societies might well fall. The other deep wiring that needs double-checking is of course that of endless competition and individualist comparisons to define one's own worth and value.

Interestingly, with these observations we come close to Asian wisdom that has conceived of happiness as an existential and social concept all along. It stands for a way of leading a life that is content overall and in which you feel able to master challenges and enjoy what you are given. In Buddhist ethics and philosophy, as the Bhutanese example of Gross National Happiness or GNH will show in Chapter 4 a high degree of well-being for some individuals does not count as an achievement if others in the community are suffering at lower levels. The Greek term eudaimonia, as used by Aristotle, has a similar meaning. It describes happiness as an activity rather than an emotional state: Happy individuals are capable of living up to the 
potentials of human nature and this leads to virtuous engagement for the common good. For a comprehensive overview of different definitions of happiness see the crowd-sourced Wikipedia.

So, sometimes it feels as though innovation is not always about finding new ideas and evidence but also about remembering old wisdom. After all, if thought through to its logical conclusion, the stark utopia and grand narrative of endless gain is a desperate one. There is no happy ending if humans can simply never get enough. As the numbers cited have shown, the threshold of what people report they need to feel good keeps on growing with the wealth of society as a whole. In this development vision we can never reach satisfaction. Thus, a culture and society nested in mind-sets and institutions of endless economic growth and competition appears less a stark utopia of freedom of choice and happiness, and more a dystopia of never being able to enjoy and relax.

\subsection{How Mainstream Economics Views Nature and Its Governance}

The second light green column of Table 3.1 assembles central concepts that mainstream economics applies when dealing with nature: forests, oceans, mountains, fields, deserts and the animals living in those locations. It provides the analytical tools available when addressing the second of the Brundtland Report's key qualifiers of sustainable development. That is "the idea of limitations imposed by the state of technology and social organization on the environment's ability to meet present and future needs" (WCED 1987: 41). This is relevant for current generations and for safeguarding the livelihoods and well-being of future generations, and the way the issue is phrased is very important. The message is usually framed wrongly. In line with key thinkers during the Enlightenment movement (most prominently Thomas Malthus), nature is depicted as imposing limits on human development, of which there seems to be only one right, linear version.

However, by using instead the relational complex systems view that natural sciences offer in the twenty-first century, we see that it is the manner and degree of human interference with nature's ability to reproduce its wealth that is backfiring. If we change our ideas and goals of development or progress, our choice of technology and social organization, humans and nature can both flourish over the long run. And from a less anthropocentric point of view, flourishing nature is an ethical goal in itself, totally independent of the use value that this provides for humans.

The Second Enlightenment mindshift replaces the lens of 'fighting nature's limits by extracting more natural resources faster' with one of 'aligning production and consumption patterns with her circular reproductive cycles.' This requires descriptions, measures and models that illuminate where and how human interference hampers ecological laws. 
As we can see from the production function in Fig. 3.1, non-production-related environmental benefits or waste impacts on nature do not figure in mainstream thought unless producers need to pay a price for them. This way it is only viewed as a fictitious commodity, an input factor whose price producers will try to lower in order to stay competitive. The best mechanism to counter this trend and govern scarce resources is to 'get the prices right' so that markets avoid exhausting resources. With increasing scarcity, they become more expensive and therefore unattractive for continued use, hence an alternative will be found. Nature is thus not viewed as a web of life but as a heap of resources whose chunks have different exchange values (prices), depending on their scarcity. Degradation does not matter as long as alternative resources or technologies can fill the spot in production chains.

The solution to this problem requires more than merely grouping input factors into social, human, manufactured, and natural capital. As long as the models freely exchange one type of capital for another in doing the math on successful development, we see nothing of the real world changes underneath. On the input side the models track flows of single chunks of nature (e.g., cubic meters of wood) but are blind to the laws of their reproduction, which would help identify how, or which, important resources are renewed at what rate (how quickly does a forest grow and which soils are necessary for that?) and which stocks are indeed limited and therefore need careful exploitation if long-term use is necessary. Regarding the output side, superficial exchange value (market prices) says nothing about the actual use values (need satisfiers) that were generated. Growing output in the financial sector, for example, counts as positive growth in GDP standards even if it results from speculative gains on staple food commodities that make the prices of these prohibitively high for hungry people. From this point of view there is nothing beyond the economic sphere and everything within it can be converted into everything else-and nothing really gets lost. Everything is either capital as expressed in market prices or invisible.

This is why economists like Daly have argued for the introduction of non-monetized benchmarks, warning of "uneconomic growth" in which monetized indicators like GDP still show growth even though the use value (utility) created for humans becomes negative and/or natural capital stocks are destroyed beyond recovery rate. The following sections will pick up on these aspects by zooming in on each of the key concepts captured in Table 3.1 that refer to governing nature.

\subsubsection{What Types of Capital Exist and Where Do They Come from?}

As in Sect. 3.1, I would like to start this discussion by presenting the typical mainstream economic model that students are shown when studying macroeconomic dynamics. Figures 3.1 and 3.2 highlight the blind spots when thinking about 


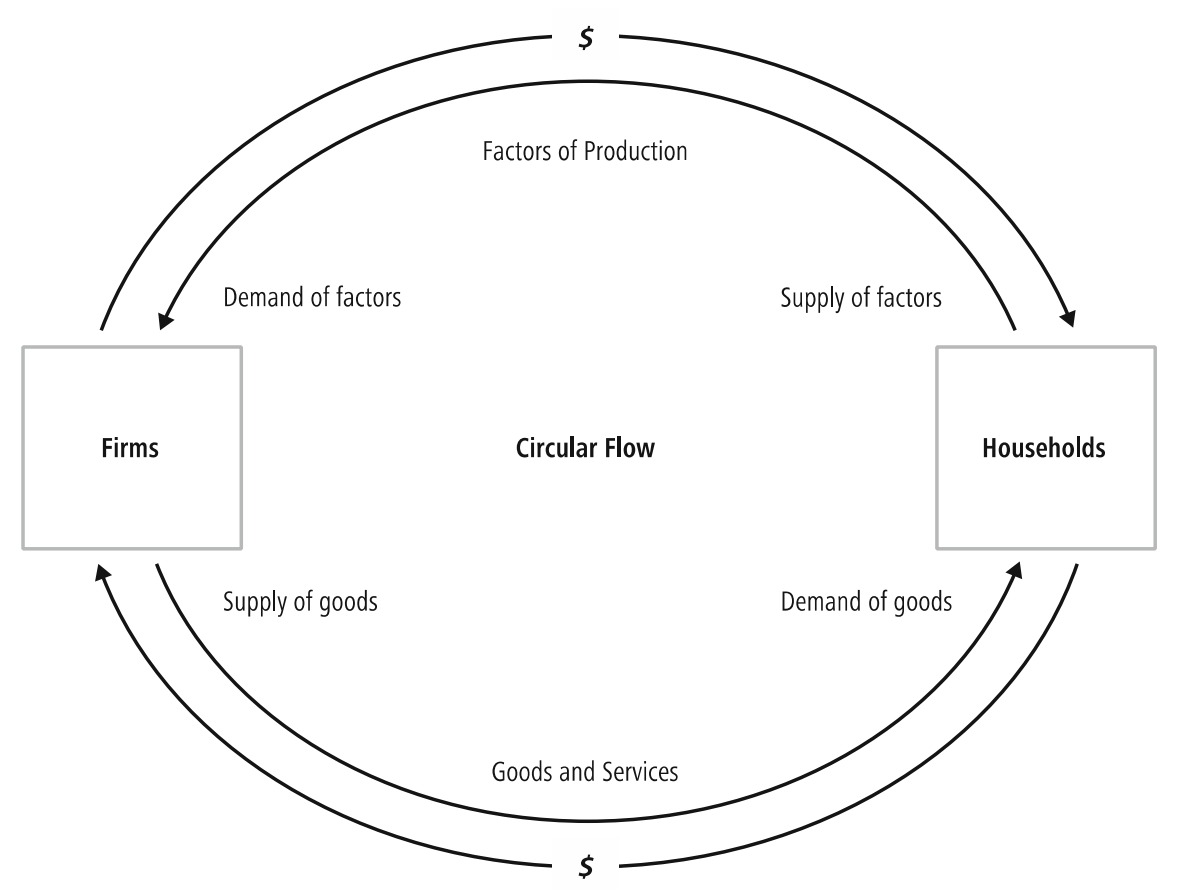

Fig. 3.3 Mainstream economics model of the economy. Source Daly/Farley (2010: 25)

production processes and here we turn to the model of an entire economic system. It consists of two main actor groups, producers or firms and consumers or households. The resulting image is that of a circular flow of goods and services and factors of production (labor, land and capital) in a closed loop, guided by price signals (Fig. 3.3).

In his discussion of how complexity economics diverges from this paradigm, Beinhocker returned to his "half-baked physics" analogy, which rests on the First Law of Thermodynamics, also called the Conservation of Energy Principle. It was developed in the late eighteenth century and explains that in isolated or closed systems energy is neither created nor destroyed but merely changes its forms. You always have the same total: if net energy or heat is supplied to a system it equals the net work done by the system. Energy in economics is capital. Similar to utility it needs some measurement unit and this is once again money. The value of pieces of capital is expressed in market prices, so what counts is their "exchange value."

The Second Law of Thermodynamics followed midway through the nineteenth century and refers to the irreversibility of natural processes. It states that every time energy changes its form there is an increase in entropy, a measure of disorder or randomness. This means that continued activity will eventually make any closed or isolated system decay into disorder. Only open systems, using energy and matter 
flowing through, can counter this process. They can create syntropy-order, structure and patterns - by taking the necessary energy from connected systems. This is how nature uses the sun's energy for its evolutionary reproduction circuitsand how humans use nature.

Yet, this fully baked physics did not make it into mainstream economic models. The sources of energy remain invisible in mainstream economic models. Only the prices of what is exchanged are tracked. In their classic textbook Ecological Economics: Principles and Applications (2010) famous ecological economists Herman Daly and Joshua Farley summarize the loss of information so brilliantly that it is worth quoting at length:

\footnotetext{
What is it that is really flowing around and around in a circle in the circular flow vision? Is it really physical goods and services, and physical laborers and land and resources? No. It is only abstract exchange value, the purchasing power represented by these physical things. The 'soul' embodied in goods by the firms is abstract exchange value. When goods arrive at the households, the 'soul' of exchange value jumps out of its embodiment in goods and takes on the body of factors for its return trip to the firms, whereupon it jumps out of the body of factors and reincorporates itself once again into goods, and so on. But what happens to all the discarded bodies of goods and factors as the soul of exchange value transmigrates from firms to households and back ad infinitum? (Daly/Farley 2010: 28)
}

The real-world impact that the discarded bodies create lies beyond what is captured by capital accounting. Mines, wells, fishing grounds or cropland are built up and replenished according to their own logics. They are not simply available because someone demands them and is willing to pay a price. Nor are their capacities to absorb and store all the discarded bodies endless.

One estimate puts the total amount of extracted raw materials that end up as solid waste at 12 billion tons per year, of which 4 billion tons are generated in OECD countries alone (OECD 2014b: 10). The only way that such waste enters the exchange value circle is in form of the cost of collecting it and storing it somewhere. What remains unaccounted for is how nature then deals with this output, which might include gigantic garbage dumps, sealed radioactive containers, or a field of plastic the size of Texas floating in the Pacific Ocean. Even more difficult to account for, in particular in price signals, is non-material waste like emissions from burning fossil fuels, the declining fertility of billions of hectares of soil, the seepage of chemicals from agriculture into the earth and then into the oceans, destroying coral reefs.

The first UN World Conference on Sustainable Development in 1992 in Rio de Janeiro acknowledged that the management of ecosystems might need different governance mechanisms than that of conventional markets. Thus, Rio created conventions for tackling climate change, biodiversity loss and desertification. Still, economic growth impacts are always of concern and already in the 1970s economists had engaged with nature by making it an input factor of production functions. Somewhat as all the pleasure (output) to be had was stuffed into the abstract container term of utility, 1970s economists simply expanded the term 'capital' to include everything that could be used productively (input). Both are handily measured in monetary terms, so that predictive models can be run. 
US economists Robert Solow and John Hartwick then embarked on the question of the intergenerational allocation of natural resources and their basic idea became that of 'capital substitutability.' In line with closed system exchange value conversion assumptions, capital substitutability holds that while each generation should have the same amount of capital available, the composition of its overall stock can vary. For example, natural capital can be degraded as long as man-made capital is increased to the same value (Solow 1986: 141-149).

When the Rio Summit put intergenerational distribution of the means for need satisfaction center stage, this concept was included in the measures recommended for tracking if development had become sustainable. But instead of making calculations according to the biophysical laws of nature, policymakers used the laws of exchange value for natural assets. Capital substitutability offered a way to integrate the environment with economic calculations that need not upset the human self-image: economic growth could happily continue. It might also have helped that Robert Solow won the Nobel Prize for Economics in 1987, the same year that the Brundtland Report came out.

Natural scientists and ecological economists were and are critical of this move and demand that there should be limits to the use of market pricing in a good governance regime. Let us explore their criticisms and alternative concepts in more detail.

\subsubsection{Market Prices and the Allocation or Protection of Scarce Resources}

The term that mainstream economics uses when its models' predictions go awry is 'market failure.' There is no question as to whether markets are always the best solution; the problem is always that some policymaker was silly enough to intervene in the equilibrating checks and balances of exchange value. Of course there are many, many cases where market prices are distorted, often because private actors also seek to manipulate them. The aim of making them tell the 'truth' about the environmental and social costs involved in producing a product or service is a necessary one. But it is not sufficient to govern human-nature relations in a sustainable manner.

Here are some examples in which prices did not secure good allocation or prevent overexploitation of nature's riches. First, when the natural resources affected are needed for subsistence. The direct survival means of many of the poorest people in the world today need to be protected against price hikes fuelled by speculative interests that aggravate supply crises. Individual economic gain aspirations need to yield to survival needs. Yet, if there is a detectable pattern, it seems to be that instead of prioritizing the needs of the poor, exchange value orientation means prioritizing the rich with purchasing power. Second, and as a consequence of unequal wealth generation, market prices do not necessarily deter rich people from 
consuming things that prices indicate have become scarce. In a materialist culture of competitive status-seeking, paying more means showing off-as the term 'conspicuous consumption' implies.

One example of this is the threatened Japanese bluefin tuna, whose very high price has not reduced consumption, but actually made it even more desirable. Indeed, in 2013 the first tuna of the year was sold for almost \$2 million. This pretty irrational market failure was described as 'Sushinomics' by the The Atlantic (Narula 2014). It bears out Daly and Farley's observation that the maximum economically and technologically feasible exploitation of nature might just be too high. Even from a blatantly anthropocentric point of view, this will have disutility effects on all the manufactured goods whose successful use is dependent on an intact environment, for example, diving masks worn to observe tuna. Nature, Daly and Farley note, "provides a complementary service without which the utilities of most consumer goods are not very great" (Daly/Farley 2010: 163).

Worse, there are no price signals for all non-commodifiable ecosystem services. These include the entire cyclical management of freshwater or a healthy atmosphere in which multiple ecosystems like rivers, oceans, soils and forests are involved in cleaning water and air so that they are fit for human consumption. Emission trading schemes represent attempts to create markets for the waste absorbing or usefully transforming sinks that form part of these ecosystems. In these schemes, producers are supposed to buy $\mathrm{CO}_{2}$ emission rights (e.g., the European Emissions Trading System), or the owners of forests are compensated for the $\mathrm{CO}_{2}$ extracted from the atmosphere (e.g., the REDD+ mechanism under the UN Framework Convention for Climate Change). The goal is to disincentivize both the use of $\mathrm{CO}_{2}$-emitting resources and the destruction of $\mathrm{CO}_{2}$-absorbing ones so that the balance, or carrying capacity of the atmosphere, can be restored.

However, the creation of markets for ecosystem services only works on single atomized units of capital, like a ton of $\mathrm{CO}_{2}$, and thus tells us little about the whole web of natural life. Living species interact and form complex ecosystems with balancing feedback loops and food chains. Thus, overexploiting one type of resource, or condemning one species to extinction may seem harmless. But without an understanding of these intricate relationships, we may create a 'missing link,' glut or shortage in the dynamic reproduction circuits of basic life support systems like water supply, pollination patterns or soil fertility (Daly/Farley 2010: 75-76).

To me, it sounds like a rational risk management strategy to amend these price signals with some biophysical data tracking and sound regulations on usage limits. This is particularly important given the minimal help that price signals can provide for future-oriented precautionary governance of scarce resources: living complex systems are unpredictable precisely because these development models are built around a mechanical additive understanding in which single elements can be freely subtracted and added without changing the overall dynamic. The Assessment Reports of the IPCC, for example, calculate that, if the atmosphere is to stay within its current dynamic equilibrium, a concentration of $\mathrm{CO}_{2}$ somewhere between 350 and $450 \mathrm{ppm}$ is all that the natural cycle of $\mathrm{CO}_{2}$ transformation can take. If we exceed this amount, all the ecosystems involved in the carbon cycle face changes 
and potentially drastic ones, such as ocean acidification, sea level rise, increased flooding or, by contrast, desertification, and so on.

Meanwhile, the challenge with complex systems is that they often have delays in their feedback structures, depending on the available stocks of resources that can be used, like credit, for a certain amount of time. In addition, the effects on one resource or biophysical process are typically linked with other natural cycles and may lead to accelerated feedback loops that have nothing to do with the original human activities. This means that problems often only become visible or tangible when it is no longer easy to put a halt to the damage they are causing. The linear causality image of a kettle removed from a stove when it whistles is utterly misleading. MIT professor John Sterman and Harvard education expert Linda Booth-Sweeney explain this "wrong mental model" in the context of climate change. It assumes, they argue, that it will only

\section{require short delays in all the links in a long causal chain, stretching from the detection of adverse climate impacts to the decision to implement mitigation policies to emissions reductions to changes in atmospheric GHG [Greenhouse Gas] concentrations to radiative forcing to surface warming and finally to climate impacts, including changes in ice cover, sea level, weather patterns, agricultural productivity, the distribution of species, extinction rates, and the incidence of diseases, among others. None of these conditions hold: there are long delays in every link of the chain (Sterman/Sweeney 2007: 214).}

None of this can be captured by exchange value or market prices. The governance of nature requires multidimensional evidence instead of the typical monetized cost-benefit analyses that are popular in policymaking. In those natural protection measures, investment in education, extent of social welfare, etc., are judged by quantifying their value in monetary terms. Equipped with those numbers one can calculate when it is 'economic' to implement them. There are no general standards as to how this conversion should be done, so it is down to the ethical judgments and mind-set of the - often economics-trained-policy advisor: what is the monetary value of a human life? How much should saving thousands of lives a year through tougher pollution standards therefore be allowed to cost? When is it too expensive? Whose competitiveness might be impacted by the higher costs of production?

When it comes to presenting the 'evidence,' numerical equations radiate the aura of objectivity. But digging into what twenty-first century science tells us about nature renders equations unsuitable for sound economic governance. Ecological economists like Daly therefore demand a precautionary approach that starts from the premise that certain functions of nature - some of its laws - cannot be duplicated by humans but are essential to the continuation of human prosperity on this planet, at least for the foreseeable future. They determine the quantity of and rate at which nature develops the low entropy resources that humans use. For example, the humus in fertile soil that takes up to 2000 years to form, and the fossil fuels that started forming 300 to 400 million year ago. Likewise the way that high entropy waste in the form of emissions, chemicals and heat can be absorbed by plants, soil, water, and so on.

Sustainability economics will need to embed the exchange value loop model in the real world, argues Daly. During his time from 1988 to 1994 as a senior 
economist at the World Bank he developed a succinct set of management principles for sustainability. They show which scientific and ethical judgments are inherent in market prices and cost-benefit analyses:

- The use rate of renewable resources cannot be higher than their rate of regeneration or they are lost for future generations.

- The use of non-renewable natural resources should not exceed the discovery of alternative sources to deliver on the same function (e.g., replacing fossil fuels with solar technology).

- Emissions cannot be higher than the capacity of the natural environment to cope with them.

- Human-made threats to or excessive risks for human health and the environment should be avoided (Wikipedia 2014).

So even if one sticks with the mainstream lens of rejecting allocation decisions through laws and agreements, the question about when prices tell the environmental and social truth will be equally political. This process cannot be left to economist modelers. In democracies the process needs to be as explicit and transparent as possible. The agenda on Planetary Boundaries, or limits to growth, is about nothing else, even though its critics like to portray it as doomsday eco-dictatorship. No one is talking about people not being allowed to intervene in nature, intentionally enhance natural resources or look for artificial ones. It is about developing a good understanding of what we have and how the laws of resource reproduction coalesce so that we can manage development processes well and equitably.

This view has also been dubbed "strong sustainability" and its advocates argue that the three dimensions - social, ecological, economic - of sustainable development should capture its paradigmatic shift away from the old development imaginary. Sustainable development should not be delineated with three pillars of similar importance - the dominant icon since the Earth Summit in 1992-it should instead be portrayed as a series of embedded systems. Figure 3.4 shows that this renders the economic system - the stark utopia of the market system - the servant rather than the master of the social and environmental system. A discussion of the arguments can be found in the first Global Sustainable Development Report (2014).

In line with this paradigm, ecological economists are less interested in what might theoretically, at some point in the future, be possible if technological revolutions and yet more money were available. They are more interested in preventing the irreversible harm caused by ignoring the long period of transition required between now and then. It is from this perspective - also a great mindshift - that they argue for future development paths that will host a steady state economy that remains constant instead of exponentially expanding levels of production and consumption. Getting there would require massive transformations of many path dependencies in the economic and also social systems. But ruling them out means accepting massive transformations in the ecological and social systems, which will also impact economic systems in the mid-term. 

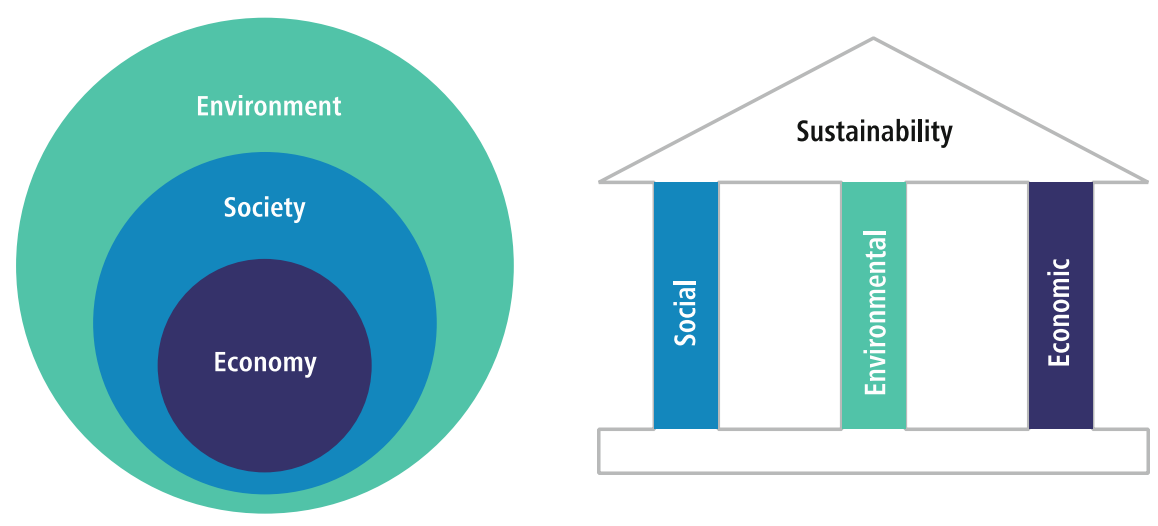

Fig. 3.4 The three-pillar versus embedded-system view of sustainable development. Source Own illustration

Maintaining an unequivocal imaginary and narrative of endless growth might be politically easier and convenient for privileged groups but cannot be backed by evidence drawn from the natural sciences of the twenty-first century.

\subsubsection{Checking Nature's Safe Operating Spaces for Human Growth Aspirations}

The third and fourth rows in Table 3.1 bring us to a deeper understanding of why only economists can argue for unlimited growth. The most popular argument we hear is that one can decouple economic growth from natural resource use. Make more with less. There is nothing to say against the efficient and sparing use of natural resources, but relative savings should not be confused with an absolute reduction of human-caused exploitation levels. Raw material extraction levels reached 70 billion tons in 2008 . This is unprecedented not only in total but also in the amount per person: about 10.5 tons. Of course these numbers vary widely between countries, being lower in India and China and higher in Australia and Chile (Wiedmann et al. 2015: 6273-75). So it seems like good news that global average resource intensity or relative decoupling as measured in the standard indicator of Domestic Material Consumption per unit of GDP (DMC/GDP) has decreased significantly from $3.6 \mathrm{~kg} / \$$ in 1900 to $1.3 \mathrm{~kg} / \$$ in 2005 (Wiedmann et al. 2015: 6271). Otherwise the world would look like a big mine shaft. With this indicator, as OECD reports summarize, it also looks like some countries such as Canada, Germany, Italy and Japan have decoupled DMC from economic growth in absolute terms. They get richer but no longer need more natural resources.

Yet, a discussion of the rebound effect hinted that current consumption and market patterns do give price signals that suggest using fewer resources per product 
or service (as long as there are prices on the natural resources or waste created) but don't really suggest using fewer resources in total. 'Making more' and 'consuming more' remain the dominant partners in the formula.

One study that tried to untangle what seem to be contradicting observations was undertaken by an international group of ecological economists working with Thomas Wiedmann and published as 'The material footprint of nations' in the Proceedings of the National Academy of Sciences of the US (PNAS). They show that DMC, despite being the lead indicator for the Green Growth and Green Economy studies and strategies of the EU, OECD and also the UN Environment Programme (UNEP), hosts two big blind spots:

(1) it captures only those materials that made it into the final products and leaves all the waste and extraction created in the process unaccounted for;

(2) it allocates the resource extraction figures in the country where they occur and not in the countries where the products they are used for are consumed.

This means that all the environmental impacts associated with extracting and processing raw materials into goods fall out of the picture. These include water resource depletion and pollution, soil erosion, biodiversity loss, mine tailings, and natural destruction or pollution through spillages and agrochemicals. In particular the production of metals involves digging out ores and turning them into concentrated commodities. It also means the obfuscation of the way in which the globalized supply chains rich countries use to primarily import materials or even semi-finished products relegate consumption and natural impact to two separate balance sheets (Wiedmann et al. 2015: 6273). This 'leakage' effect has already been criticized in connection with the commonly used statistics and thus negotiations about $\mathrm{CO}_{2}$ reduction commitments.

To tackle these blind spots the research team used the Material Footprint (MF) as a consumption rather than production indicator. It measures all the natural impact that a particular economy creates, including unused extraction, and regardless of where resources happen to be taken out. The indicator has also been called Total Material Requirement (TMR) and comparing it with DMC shows a "process of externalization of resource-intensive processes of mature economies" in which the MF per capita becomes considerably larger than the standard measure (ibid.: 6273). The United Kingdom and Japan are at the extreme end not only regarding this statistical aberration but also in their dependence on imports for their levels of final consumption.

When checking for correlations with factors that influence the levels of MFsuch as availability of raw materials, density of population or GDP per capita- the findings confirm "a very strong link found previously between growth in building materials, ores, and fossil fuels use and economic growth in most of developing Asia, most notably in China," and, as in many other studies working with footprint indicators, with levels of income. For "a $10 \%$ increase in wealth, the MF would increase by $6 \%$ " (Wiedmann et al. 2015: 6273). 
So while it is commonly argued that environmental pollution drops once certain thresholds of income are reached (the famous Kuznet's curve) this cannot be documented in such meta studies. Instead they bring to the fore structural questions that will become vital in the SDG agenda, e.g., which development model can claim to be sustainable? Surely not those whose MFs overshoot what would be a fair share of the globally available resources by a factor of five to ten?

This is what Stefan Bringezu, member of the UNEP International Resource Panel, found when undertaking a per-capita calculation of fair shares of all natural resources. A "potential sustainability corridor" would be reached by 2050 if the Total Material Consumption (TMC) of abiotic or non-renewable resources lay between 6 and 12 tons per person, the TMC of biotic or renewable resources below 2 tons per person, and the Raw Material Consumption (RMC) of used biotic and abiotic materials between 3 and 6 tons per person. He concludes that "[F]or policy, a '10-2-5 target triplet' can provide orientation, when the three indicators are assigned values of 10, 2, and 5 t/person, respectively" (Bringezu 2015: 25). To put these numbers into perspective: for rich countries they mean a reduction of 40 $90 \%$ in each of the indicators based on 2014 use levels (ibid.: 42-45).

We see that before decoupling strategies can be called successful, their calculations and indicators need to tell the true story behind any Green Growth path, especially for a global agenda. The OECD as well as the EU have come around to expressing the limitations of DMC but have not accepted absolute targets for TMR as Bringezu suggests.

But why are natural scientists so concerned with defining a sustainability corridor or operating space? Because market prices can only tell the truth about social and environmental impact when these are realistically estimated. If an estimate is undertaken with a mechanical engineering mind-set it will look very different from one undertaken with an embedded systems view. According to the latter, ecosystems already risk losing the stable and resilient environmental characteristics to which humanity is accustomed. This is what the term 'Anthropocene' stands for: the 10,000 benign years of the Holocene have been ended by human interference with Earth's reproductive processes. This earth system science shows us that if we extract from the planet all that is technologically and economically feasible to harvest, it will be far too much for the planet to sustain. Price signals come too late unless caps for maximum exploitation are defined.

The research agenda on 'Planetary Boundaries' aims to avoid ecosystem cycles or reproduction being 'tipped out' of dynamic equilibrium. Twenty-six scientists published an article on Planetary Boundaries in the journal Nature in 2009 to highlight the fact that three out of nine central dimensions of Earth's productive processes were already in a state of overexploitation: namely $\mathrm{CO}_{2}$ and nitrogen cycles, and the rate of biodiversity loss (Rockström et al. 2009). The title dovetails well with the mainstream image of nature limiting human growth aspirations. Yet, the article is a plea to understand these boundaries and to align human activity with them. This is what the subtitle "A Safe Operating Space for Humanity" means (Table 3.3). 
Table 3.3 Defining Planetary Boundaries

\begin{tabular}{|c|c|c|c|c|c|}
\hline $\begin{array}{l}\text { Earth-system } \\
\text { process }\end{array}$ & Control variable & $\begin{array}{l}\text { Boundary } \\
\text { value }\end{array}$ & $\begin{array}{l}\text { Current } \\
\text { value }\end{array}$ & $\begin{array}{l}\text { Boundary } \\
\text { crossed }\end{array}$ & $\begin{array}{l}\text { Preindustrial } \\
\text { value }\end{array}$ \\
\hline \multirow[t]{2}{*}{ 1. Climate change } & $\begin{array}{l}\text { Atmospheric } \\
\text { carbon dioxide } \\
\text { concentration (ppm } \\
\text { by volume) [25] } \\
\text { See also: Tipping } \\
\text { point (climatology) }\end{array}$ & 350 & 387 & Yes & 280 \\
\hline & $\begin{array}{l}\text { Alternatively: } \\
\text { Increase in radiative } \\
\text { forcing }\left(\mathrm{W} / \mathrm{m}^{2}\right) \\
\text { since the start of the } \\
\text { industrial } \\
\text { revolution }(\sim 1750)\end{array}$ & 1.0 & 1.5 & Yes & 0 \\
\hline $\begin{array}{l}\text { 2. Biodiversity } \\
\text { loss }\end{array}$ & $\begin{array}{l}\text { Extinction rate } \\
\text { (number of species } \\
\text { per million per } \\
\text { year) }\end{array}$ & 10 & $>100$ & Yes & $0.1-1$ \\
\hline \multirow[t]{2}{*}{ 3. Biogeochemical } & $\begin{array}{l}\text { (a) anthropogenic } \\
\text { nitrogen removed } \\
\text { from the } \\
\text { atmosphere } \\
\text { (millions of tonnes } \\
\text { per year) }\end{array}$ & 35 & 121 & Yes & 0 \\
\hline & $\begin{array}{l}\text { (b) anthropogenic } \\
\text { phosphorus going } \\
\text { into the oceans } \\
\text { (millions of tonnes } \\
\text { per year) }\end{array}$ & 11 & $8.5-9.5$ & No & -1 \\
\hline $\begin{array}{l}\text { 4. Ocean } \\
\text { acidification }\end{array}$ & $\begin{array}{l}\text { Global mean } \\
\text { saturation state of } \\
\text { aragonite in surface } \\
\text { seawater (omega } \\
\text { units) }\end{array}$ & 2.75 & 2.90 & No & 3.44 \\
\hline 5. Land use & $\begin{array}{l}\text { Land surface } \\
\text { converted to } \\
\text { cropland (\%) }\end{array}$ & 15 & 11.7 & No & Low \\
\hline 6. Freshwater & $\begin{array}{l}\text { Global human } \\
\text { consumption of } \\
\text { water }(3 \mathrm{~km} / \text { year })\end{array}$ & 4000 & 2600 & No & 415 \\
\hline 7. Ozone depletion & $\begin{array}{l}\text { Stratospheric ozone } \\
\text { concentration } \\
\text { (Dobson units) }\end{array}$ & 276 & 283 & No & 290 \\
\hline $\begin{array}{l}\text { 8. Atmospheric } \\
\text { aerosols }\end{array}$ & $\begin{array}{l}\text { Overall particulate } \\
\text { concentration in the } \\
\text { atmosphere, on a } \\
\text { regional basis }\end{array}$ & \multicolumn{4}{|c|}{ Not yet quantified } \\
\hline
\end{tabular}


Table 3.3 (continued)

\begin{tabular}{l|l|l|l|l|l}
\hline $\begin{array}{l}\text { Earth-system } \\
\text { process }\end{array}$ & Control variable & $\begin{array}{l}\text { Boundary } \\
\text { value }\end{array}$ & $\begin{array}{l}\text { Current } \\
\text { value }\end{array}$ & $\begin{array}{l}\text { Boundary } \\
\text { crossed }\end{array}$ & $\begin{array}{l}\text { Preindustrial } \\
\text { value }\end{array}$ \\
\hline $\begin{array}{l}\text { 9. Chemical } \\
\text { pollution }\end{array}$ & $\begin{array}{l}\text { Concentration of } \\
\text { toxic substances, } \\
\text { plastics, endocrine } \\
\text { disruptors, heavy } \\
\text { metals, and } \\
\text { radioactive } \\
\text { contamination into } \\
\text { the environment }\end{array}$ & Not yet quantified & & \\
\hline
\end{tabular}

Source Rockström et al. (2009: 472-475)

The concept of Planetary Boundaries was developed to host an ongoing process of refinement in line with improving data and computer simulations (see, for example, Steffen et al. 2015). The work includes the identification of the best indicators for the remaining two of the nine dimensions and to understand regional thresholds in line with the actual biophysical realities in these areas. Regional assessments are necessary because, in certain regions, tipping points in some of the dimensions will be reached much more quickly than in the global average. There are prime examples in the cases of freshwater provision and soil erosion.

Another research angle addresses the correlations between the dimensions, for example, of how land-use pattern changes impact on $\mathrm{CO}_{2}$ emissions, freshwater availability, and biodiversity. This is necessary because otherwise predictive calculations as to how many resources are left for production, or how they can be substituted by renewable ones may end up relying on one source several times over.

This issue is currently emerging with the growing agenda for a 'bio-economy.' Raw material shortages are to be circumvented by using biomass and natural fibers instead. While the political strategies tend to insist that food production has to have priority over industrial use, quantifications on what this means in practice are missing. The German bio-economy strategy of June 2013, for example, aligns its goals with those of the German sustainable development strategy that seeks to limit the conversion of land for settlement, transport, production, or agriculture from 87 to 30 ha daily by 2020 . However, this policy fails to provide any safeguards for maximum conversion limits, if Planetary Boundaries are to remain intact (Destatis 2012: 15). This relative target still allows for an indefinite 10,680 ha to be converted every year after 2020. Over the long run Germany could turn every forest into a field for biomass.

It was research scientists at the UN International Resource Panel that shed some light onto how much global cropland is actually available to sustainably supply food for 9-10 billion people. They undertook extensive work to identify where thresholds lie for land-use changes if biodiversity loss, release of $\mathrm{CO}_{2}$, disruption of water and nutrient cycles and the loss of fertile soils should not plummet under their Planetary Boundary levels. 
Table 3.4 Land use predictions by the UN International Resource Panel

\begin{tabular}{l|l|l|l}
\hline $\begin{array}{l}\text { Business-as-usual } \\
\text { expansion }\end{array}$ & $\begin{array}{l}\text { Low } \\
\text { estimate } \\
\text { (Mha) }\end{array}$ & $\begin{array}{l}\text { High } \\
\text { estimate } \\
\text { (Mha) }\end{array}$ & Source \\
\hline Food supply & 71 & 300 & $\begin{array}{l}\text { Based on Bruinsma (2009), } \\
\text { RFA (2008), Bringezu et al. (2009a) }\end{array}$ \\
\hline Biofuel supply & 48 & 80 & Based on Fischer (2009), IEA (2011) \\
\hline Biomaterial supply & 4 & 115 & $\begin{array}{l}\text { Based on Colwill et al. (2001), } \\
\text { Raschka/Carus (2012) }\end{array}$ \\
\hline Net expansion & $\mathbf{1 2 3}$ & $\mathbf{4 9 5}$ & Based on Electris et al. (2009) \\
\hline $\begin{array}{l}\text { Compensation for } \\
\text { built environment }\end{array}$ & 107 & 129 & Based on Scherr (1999) \\
\hline $\begin{array}{l}\text { Compensation for } \\
\text { soil degradation }\end{array}$ & 90 & 225 & \\
\hline Gross expansion & $\mathbf{3 2 0}$ & $\mathbf{8 4 9}$ & \\
\hline
\end{tabular}

Source UNEP (2014: 20)

Their 2014 report, Assessing Global Land Use: Balancing Consumption with Sustainable Supply, concludes that humanity's safe operating space ends at a total of 1640 million hectares of global cropland, which leaves roughly an additional 100 million hectares yet to be converted. Were current trends to continue, this limit would be reached by 2020 and conversion would not stop there but, as can be seen in Table 3.4, eat up an additional 320-849 million hectares before demand leveled off (UNEP 2014: 23-25). To prevent this the report recommends that significant changes in agricultural practices, production and consumption patterns and the composition of diets are more imperative than the growth of a land-guzzling bio-economy.

Of course, the ranges calculated for the Planetary Boundaries are contested. Interestingly, most of the criticism comes from within the strong sustainability camp and is lodged by biologists or experts in the individual dimensions. They argue that the identification of precise thresholds is still too numerical and too mechanical, further supporting the persistence of the managerial paradigm of exploiting nature as quickly and effectively as possible. Others say that global boundaries cannot tell us much about regional challenges, among which the availability of land, fresh water or oceans, for example, differ widely.

Another caveat concerns the absence of non-renewable resources in what has become the most prominent framework in addressing the sustainable governance of nature. As the discussion on the MF showed, this omission obscures much of the picture of how much natural capital is left. It also showed that even if the boundary or carrying capacity numbers are not totally correct, the trends toward overexploitation are so clearly documented that swiftly and significantly changing course should be the rational strategy.

One crucial element in this context is indeed the much more efficient use of natural resources, the improvement of recycling rates, adoption of modular designs and a choice of materials that allows for reintegration into the natural cycles. 
Measures and incentives as well as policy frameworks are needed toward this end. Yet, doing all of this without challenging the output indicator of the decoupling agenda, GDP, keeps the thinking linearly, geared at maximum possible exploitation: which means, for example, that species extinction rates ten times the average rate over time are acceptable simply because they would not destroy human welfare.

\subsubsection{How Does Exchange Value Governance Impact Living Systems?}

Just as introducing the logic of cost-benefit thinking in more and more areas of life numbs people to realizing what is really at stake, the logic of capital substitutability turns the perceptions of the webs of life of which nature is composed into one of a demand-satisfying raw material storage whose overexploitation will spur human ingenuity into finding substitute input factors. Ironically, the concept was developed to recognize nature's importance in economic processes but in the end made nature invisible.

It was John Hartwick who translated the concept of capital substitutability into policy guidelines in the 1980s, and after the Rio Summit in 1992 these became the measurement standards promoted by powerful international institutions. According to the Hartwick-Solow rule, sustainable development is reached as long as the rent or benefit made from degrading natural resources is invested in the augmentation of man-made, i.e., social and human capital (Hartwick 1978: 347-354). As a consequence, the world started changing its accounting systems, incorporating nature into the most influential measure of economic performance and progress, GDP.

GDP expresses the sum of the market value of all final goods and services produced by firms, individuals and the government in any given time within one country's borders. It is usually calculated annually and, with some minimal exceptions, nothing is counted that is not purchased within that year. It also provides the base line for the most common indicator of poverty and standard of living, GDP per capita. The total of GDP is divided by the number of people living in a country.

The criticism of GDP as a measure has many nuances but three points are always made:

- GDP violates accounting rules because it lumps together costs and benefits: Cleaning up after natural disasters or having to install thick absorption walls along highways for noise protection create payments for services and products but are actually defensive expenditures. They only restore or maintain a similar level of 'wealth' but do not increase it.

- GDP ignores all value created or depleted that has not been captured by market prices. This includes household and volunteer work, education and caring for children and the aged. Meanwhile, once someone starts being paid for this type 
of work, it automatically registers as 'growth' even though nothing new has been created. Destruction of natural resources like healthy oceans, forests or landscapes is growth, once someone pays for their raw materials, but the same destruction is invisible if they do not.

- GDP is blind to the effects of distribution. The overall sum does not show who has been receiving which amount of income from exchanging the products and services whose market prices are aggregated. The per capita GDP of a country may therefore rise while its poverty levels stay the same.

After a first wave of debate about the blind spots of GDP as a benchmark for development in the 1970s, the ever more tangible, negative effects of the economic growth development agenda have revived criticism in recent years. Since 2007, many initiatives have formed around the world, which the OECD-led online platform www.wikiprogress.org seeks to keep track of.

Before this revival, however, the capital substitutability logic had elegantly settled the challenge of environmental limits to progress: in Standard National Accounting, as used by the UN, only the formation of fixed, produced capital was counted as an investment in the future, since it is viewed as increasing the value of the assets available to society. Likewise, depreciation of the value of this type of capital was calculated as a decrease. The World Bank engaged with the critique of an undifferentiated understanding of capital and added human and environmental or natural capital because, according to the World Bank's Manual for Calculating Adjusted Net Savings, they are equally important "assets upon which the productivity and therefore well-being of a nation rest" (World Bank 2002: 4). A depletion in the stock of an asset like minerals or water means that options for future use decrease and therefore should be calculated as a disinvestment.

However - and here we find the Hartwick-Solow rule - the net opportunity costs for future citizens are not necessarily negative if the profits made from depletion are invested elsewhere. The new indicator of Genuine Savings Accounting or Adjusted Net Savings expresses this substitutability view by subtracting a country's natural capital depletion and pollution from its Gross National Income (GNI), which is similar to GDP but counts the production of all citizens independently of where they live.

Within the discipline of the economics of sustainability this approach has been labeled "weak sustainability" because it does not make any reference to the biophysical limits that a country might well run into even if the entire population becomes utterly smart and creative. This is different from the safe operating space mind-set and became the source of peer benchmarking activities comparing the sustainability performances of different countries. As the World Bank manual explains:

Weak sustainability assumes that any type of capital is perfectly substitutable for natural capital as an input to production. From the adjusted net savings standpoint, for example, a nation which reinvested all of its profits from the exploitation of non-renewable resources in the formation of human capital through its educational system would have imposed no net opportunity cost on the country's future 
citizens. Whether or not this is precisely true is a hotly-debated issue, and this study makes no attempt to settle the issue (World Bank 2002: 4).

In practice this means that an indicator of zero or more is viewed as sustainable development, whereas negative savings indicate that total net wealth is in decline and policy change is necessary (ibid.: 5). The most successful role models from this point of view are all those countries that apply high royalties on the extraction of their natural resources and use these to improve the social and human capital of their population, which will then spur further growth.

The 2011 World Bank report, The Changing Wealth of Nations, calculated how high the "hypothetical produced capital" of several countries would be, had they reinvested the royalties from their environmental capital accordingly. Trinidad and Tobago and Gabon could have tripled the social, human, and manufactured capital they produced between 1995 and 2005 (World Bank 2011: 16). By contrast Norway and its oil industry is always cited as the exemplary star performer.

So while Adjusted Net Saving acknowledges the growth/environment trade-off to a certain degree, its assumption of easy capital substitutability does not provide many warning signals on Planetary Boundaries. Instead it champions development role models that cannot continue if sustainable development is to be achieved. Norway is impressively rich in all forms of capital because it possesses and sells a lot of oil. The IEA predicts that about two-thirds of the oil that could be extracted and used needs to stay in the ground if climate protection goals are to be reached. How can a country win the best practice sustainability prize if its current development strategy is costing the earth?

Only monetary abstraction allows for the measurement of progress on sustainability while ecosystems are threatening to tip out of balance.

Yet, this translation of all value assets into capital is one of the explicitly mentioned advantages of the indicator. According to a World Bank manual on Adjusted Net Saving, "it presents resource and environmental issues within a framework that finance and development planning ministries can understand" (World Bank 2012: 2). But, if the outlooks on the world and the language spoken in those ministries are not conducive to finding solutions for sustainability, are they a good standard to which to convert?

\subsubsection{Summary: Governing Human-Nature Relations Successfully Depends on Understanding Them}

Market prices and indeed the economistic way of viewing the world clearly have their limits when it comes to respecting the environmental and social dimensions of sustainable development. This is why many scientists have argued for strong sustainability in which different forms of capital cannot simply be exchanged for others in measures of growth and progress. The clearest expression of this difference in paradigm is the replacement of the three-pillar image born at the 1992 Rio Summit 
with one of embedded systems. Three pillars suggest that the economic, social, and environmental dimensions are of equal quality and could potentially be served in an additive and not integrated way: some institutions take care of social things, some protect the environment and others make sure we have enough economic growth. The total sum would be sustainable development.

I found a striking example of this during my $\mathrm{PhD}$ in global political economy when I was also working as a volunteer campaigner for Friends of the Earth in its international trade program. Since 1999, international civil society organizations have formed huge coalitions behind the slogan "Our World is Not for Sale." They teamed up with small farmers, fishing communities, and workers from around the globe to voice concerns about the impact that treating everything as traded commodities managed through global market mechanisms has on livelihoods, equity and ecosystem integrity. They also pointed out that this type of world trade system would primarily benefit wealthy corporate players who are empowered to expand their activities according to their own standards.

The dominant narrative found in major global institutions, on the other hand, presented a mainstream economic spin on why a global trade system and its core institution, the World Trade Organization (WTO), would benefit poorer people: growth will trickle down after some structural adjustment periods. Moreover, environmental issues should be dealt with in the Multilateral Environmental Agreements (MEAs) but not in purely economic trade negotiations. During my research into different schools of economic thought and the role that scientific expertise plays in institutionalization processes, I came across the following eye-opening passage from the WTO's tenth anniversary report. Prepared by an "international panel of experts" it states: "It is old wisdom in many cultures that you cannot kill two birds with one stone ... So the correct policy solution is to fix the environment through an appropriate environmental policy and to maintain open trade to maximize the gains from trade and hence economic prosperity" (Sutherland et al. 2004: 14).

Wow, I thought, have these people not heard anything about the sustainable development agenda and its argument that this false dichotomy between environment and economy only holds in theoretical models? Checking the educational background of the eight experts in question, I found that all of them had studied economics at American universities. Differing passports notwithstanding, the degree of diversity of views on this panel could hardly have been lower.

Unsurprisingly, some of the most popular cases for the WTO Dispute Settlement Body and also the hottest topics in the ongoing Transatlantic Trade and Investment Partnership (TTIP) negotiations are things like import bans on tuna fished with tight nets that create incredible amounts of by-catch, genetically modified organisms or hormone-treated meats: because they are 'like products' (basically offering the same) they must not be treated differently under the purely economic trade law. They must be granted equal access to the market. Also prohibited are border tax adjustments that counter the competitive price advantage of products where 
producers did not pay the 'true' price for environmental degradation. One prime example in the context of climate protection is $\mathrm{CO}_{2}$ emission standards for products or companies: if only a handful of countries apply them, all foreign competitors whose home countries do not make them pay for emissions can thus undercut the more sustainable producers. It takes a degree in mainstream economics to continue to see environmental and economic concerns as two separate birds and abstracted 'evidence' to support such ideological claims in the expert reports. It also takes the popular growth narrative to justify even criminal pursuit of interests and fraudulent behavior as somewhat related to overall economic progress.

The Volkswagen scandal is a great demonstration of how an economic mind-set impacts the framing of events and thus the judgments of what is at stake: the EU raised its emission standards because it tried to prevent the all-encompassing effects of climate change and because air quality is the top environmental cause of premature deaths in Europe - about 100,000 a year. The World Health Organization (WHO) declared air pollution the single biggest environmental health risk (Vidal 2014). Yet, when the intentional manipulation of emission measurement software was discovered in Volkswagen cars, it was Volkswagen's plummeting stock value and the profit warnings that become headline news. The auto industry stands for $20 \%$ of Germany's GDP and some headlines are straightforwardly asking if it will depress the country's growth. Meanwhile, the German government continued to block tougher European emission standards in the same month.

Structurally, the Growth Dilemma is real. But in societies with high incomes and stagnant or negative population levels, the Growth Dilemma resembles far more a straightjacket than an economy serving human needs: structurally it means we have to always want more or else our economic systems fall into turmoil. Billions are expended on marketing so that we do not forget that what we have is not enough.

Before the institutional setup that we are used to calling 'markets' can help to bring out the best innovations and solutions for sustainable societies, they have to be set up in a way that makes sustainable solutions their goal. Science should help to understand, untangle and overcome the path dependencies that work in the other direction. The mainstream economic paradigm and its monetary mind-set, measures and metrics are not fit for this purpose. They are laden with value judgments and power relations that disguise instead of enlighten.

\subsection{How Mainstream Economics Anticipate the Future}

This final subchapter turns to the dark green row at the bottom of Table 3.1. It assesses what adopting the mainstream economic mind-sets means for addressing the overarching goal of sustainable development: i.e., governing economies so that future generations can also live satisfactory lives. To begin, mainstream economics does not so much anticipate the future as extrapolate the way the economy will be 
from the way it was. Or rather, what its models capture of the way the economy was. Most influential in this respect are the GDP growth predictions derived from the registered and aggregated monetary transactions. As long as these extrapolations are positive the future looks positive. But if GDP growth is low, financial markets get 'nervous,' investors 'lose trust' and politicians their jobs.

We have discussed the shortcomings of this measure above but what is important to add when thinking about the future is that calculating GDP trends is an exponential function. This means that zero growth, often perceived to be an equivalent to economic standstill, equals operating at the same level of output as before. And each successive percentage of growth is nominally bigger than the one before: the baseline is higher. Thus, if GDP increases by, for example, $7 \%$ in poorer countries it is likely to indicate a far smaller increase in real production output than $1 \%$ growth in a rich country. Many historically aware experts thus argue that high growth rates should be anticipated as temporary phenomena and not the norm.

In practice, zero growth does create several problems for the institutions behind today's capitalist market societies. But this is the result of the way they are set up and not some kind of natural inevitability. Much of the data presented above suggests that positive growth everywhere on the planet is not very likely to continue much longer. Yet, mainstream economics can by definition not imagine a positive future in which societies operate steady-state economies in which the throughput stays at more or less the same level. The idea of or need for constant growth is a natural law in any scenario or model for potential policy solutions.

This mental iron cage (Weber) is so strong that arguing for a no-growth or even degrowth path in rich societies is often conflated with attacking the ethical imperative of putting the needs of the poorest people first. Homo economicus cannot share existing wealth without flipping his hedonic calculus into the red. The Brundtland Report found that this would cause too much political resistance: The matter-of-fact assumption was that, "in most situations redistributive policies can only operate on increases in income" (WCED 1987: 47). Existing wealth is sacrosanct:

The number of years required to bring the poverty ratio down from 50 to $10 \%$ ranges from:

- 18-24 years if per capita income grows at $3 \%$,

- 26-36 years if it grown at $2 \%$, and

- 51-70 years if it grows only at $1 \%$.

In each case, the shorter time is associated with the redistribution of $25 \%$ of the incremental income of the richest fifth of the population and the longer period with no redistribution (WCED 1987: 47).

This no-net-loss justice definition has been, and still is, a taboo. It dovetails nicely with the liberal Enlightenment ideas behind the mainstream economic paradigm. Goal 8 in the SDGs, in particular its first target, reiterates the imperative of growth for everyone, even the super-rich: 
Goal 8. Promote sustained, inclusive and sustainable economic growth, full and productive employment and decent work for all

8.1 Sustain per capita economic growth in accordance with national circumstances and, in particular, at least $7 \%$ gross domestic product growth per annum in the least developed countries (UN 2015: 16)

This time, the explicit connection with upping the chance for redistribution policies is not even made. To be fair, there is SDG 10, "Reduce inequality within and among countries"- but its target 10.1 makes very clear that this can only happen with yet more growth: "By 2030, progressively achieve and sustain income growth of the bottom $40 \%$ of the population at a rate higher than the national average" (ibid.: 17).

\subsubsection{Which Real Qualities of Development Lie Behind Monetarized Predictions?}

The group hit hardest by the assumption that everything always keeps on growing is the one for which the sustainable development agenda was originally created: future generations. If we apply the no-net-loss justice definitions to our children and grandchildren, we need to ensure that they do not pay too little for the outcomes of investments that are paid for by generations today. The cost-benefit analyses of political decision-making on public or social investments should therefore include future costs and benefits. Who is paying and how much are they benefiting from building roads or alternative transport systems, schools or parks, renewable or fossil energy infrastructures, and so on?

For the mainstream economics mind-set the answer is as easy as it is convenient: since economic growth and per capita incomes will continue to rise exponentially, cost-benefit analyses almost always employ a social discount rate, meaning that the costs for current and future generations are not weighted equally but are comparatively higher for those living and paying today.

So, instead of being worried about how future generations will be able to satisfy their needs, weak sustainability economists worry that the current generation will take on the cost of investing, while most of the benefits are reaped by future generations. Adding the extrapolations of decreasing technology prices and increasing efficiency gains renders 'uneconomic' many of the projects that others would declare urgently necessary to keep within safe natural operating spaces. Criticism of these assumptions therefore comes from economists who bring some physical data into their equations. The seminal reports of Nicholas Stern, the 2006 The Economics of Climate Change, and the multi-scientist study The Economics of Ecosystems and Biodiversity (TEEB), coordinated by Pavan Sukhdev from 2008 onward, both explicitly call for zero or even negative discount rates. 
Both of these studies came to this conclusion because they acknowledged the fragile state of ecosystems today. For the authors, swift and significant investment is necessary to restore their balance so that they can continue to provide the biophysical conditions that humans have enjoyed for thousands of years. The sooner these investments are undertaken, the lower the eventual costs for overall development. The economic costs of inaction today will rise so quickly that GDP growth will not be able to outstrip them. Depending on the range of risks and impacts calculated, Stern predicted losing between at least $5 \%$ and more than $20 \%$ of global GDP each year indefinitely, while the TEEB report estimated the cost of biodiversity and ecosystem damage would reach $18 \%$ of global economic output by 2050 .

These claims are supported by the Oxford Martin Commission for Future Generations chaired by Pascal Lamy, a former director-general of the WTO. The primary purview of its work was to check where in current analytical concepts and governance solutions the ignorance about the future was highest. The 2013 report diagnosed a structural discrimination against future generations and concluded that in "a world of considerable uncertainty about future levels of well-being" neither linear extrapolation of trends nor short-term returns on investments in imperfect markets were suitable measures for policy design. Instead, "[W]hen evaluating the costs of action and inaction, policymakers need to ensure discounting embraces a more sophisticated appreciation of the role of ethics, risk, and the scale of possible damages in the future" (Oxford Martin Commission 2013: 61).

The science on ecosystems has shown that expecting further exponential growth everywhere in the world for a long time might not be a fair base for ethical considerations. Also, data from rich countries shows that growth rates have been slumping for two decades (Wahl/Gödderz 2012). The research results on human well-being have shown that this might not be such terrible news as long as the growth-dependent institutional setups are changed and measures corrected so that one can see what is really going on underneath the growth saga. Without this transparency and accountability the GDP and monetary output measures keep us blind to where a lot of uneconomic and unproductive 'wealth' is created and concentrated.

For the majority of people on this planet - the 3 billion still living in povertymore and better access to goods and services is urgently needed. But the dogged pursuit of absolute economic growth is not necessarily leading to this desired outcome. GDP rose from \$13 trillion with 5 billion people in 1987 to $\$ 72$ trillion with 7 billion people in 2012. Roughly speaking, this means we now live in a world with economic output equaling $\$ 10,000$ per capita compared to one equaling $\$ 2600$ per capita 25 years ago. Technically, no one should have to suffer from hunger and extreme poverty any longer. So reaching sustainability is not about more and more output of everything for everyone but about getting the right outputs in the right places into the right hands.

This is the key message that the inventors of the Genuine Progress Indicator (GPI) and its predecessor, the Index of Sustainable Economic Welfare (ISEW) want to illustrate. The GPI seeks to measure how economic growth can actually destroy 
social, human and environmental wealth and this methodology is mirrored in other indices like the National Welfare Index (NWI) in Germany. While adhering to a monetary valuation of progress, these indicators make an effort to identify the 'use value' created or depleted in the course of a particular path of development. Starting with the exchange value numbers of GDP, these are adjusted by using 24 different components that express gains or losses in social, natural and human capital. These include, for example, pollution and ozone levels, $\mathrm{CO}_{2}$ emissions, loss of farmland and primary forests and, in line with many well-being findings, income distribution, crime rates, loss of leisure time and also the time people spend in unpleasant activities like commuting. The benefits of non-marketized work at home, or as volunteers, are added as increases in wealth by counting the amount that it would cost to employ someone to do the babysitting and cleaning etc. (Genuine Progress 2014).

The overall goal is not to create an alternative cumulative indicator of sustainable development, as the information loss through monetarization and high aggregation levels prevails. The GPI was and is intended to deliver a warning as to where increased GDP contrasts with negative individual and social experiences, i.e., when uneconomic growth is reached and the marginal benefits of more GDP growth are lower than its marginal costs.

A growing group of researchers and some governments have calculated GPI per capita and compared results with GDP per capita. Similarly to Easterlin's findings, they observed a parting of the two curves at a certain point of development. In a 2013 journal article, many of the leading scholars in ecological economics like Robert Costanza, Tim Jackson and John Talberth brought together the insights of GPI calculations in 17 countries from five continents, representing $53 \%$ of the world's population. Next to an assessment of where the costs of GDP growth start to outweigh its benefits they also compared GPI per capita findings with other indicators like ecological footprint, the UN Development Programme or UNDP's Human Development Index or HDI and life satisfaction surveys in those countries (Kubiszewski et al. 2013).

By using Purchasing Power Parity to convert all GPI and GDP findings into 2005 US dollars, they added up all the country data into Global GDP and GPI per capita figures to compare their developments. While the authors do not claim their figures were absolutely accurate, as both GPI and GDP are hard to determine, the trends are clear (Fig. 3.5).

The authors identified the start of uneconomic growth on a global scale in the late 1970s: "Global GPI/capita peaked in 1978, about the same time that global Ecological Footprint exceeded global Biocapacity. Life Satisfaction in almost all countries has also not improved significantly since 1975. Globally, GPI/capita does not increase beyond a GDP/capita of around \$7000/capita" (Kubiszewski et al. 2013: 57). The primary policy recommendation taken from these findings comes very close to the Brundtland Report's redistribution goal but without declaring that we first need to grow more: "If we distributed income more equitably around the planet, the current world GDP ( $\$ 67$ trillion/year) could support 9.6 billion people at \$7000/capita" (Kubiszewski et al. 2013). In 2012 we had already reached a global 


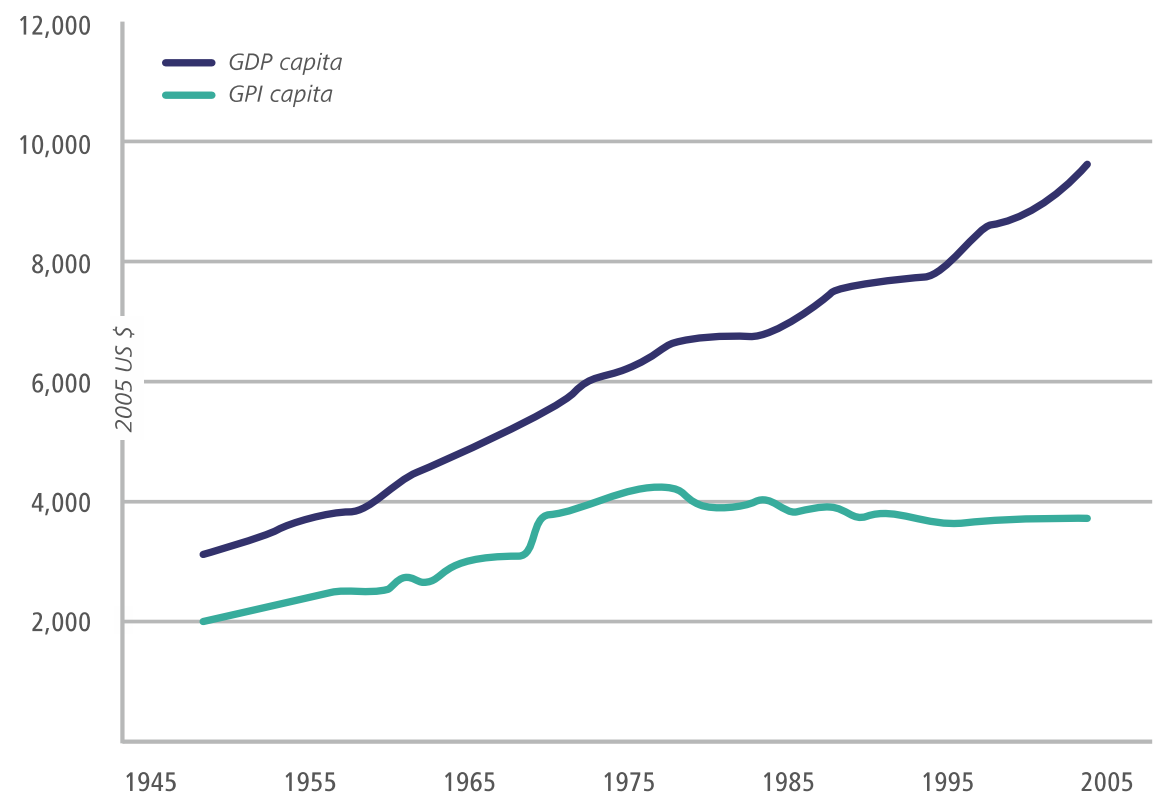

Fig. 3.5 Comparing world GDP/capita and world GPI/capita trends. Source Kubiszewski et al. (2013: 63)

GDP of $\$ 72$ trillion. So what do these impressive numbers say about ubiquitous scarcity and thus the endless need to grow?

A proper examination of which resources are scarce, which are not, and how all of them are allocated, pushes economic accounting to the sidelines and puts ethics, political will and power relations center stage. We see utterly wasteful and unjust consumption, production and distribution patterns.

Tracking the actual output of food, for example, shows that we have what we need to feed everyone well. According to the UN's Food and Agriculture Organization, roughly one third of what is produced for human consumption is never eaten. This amounts to about 1.3 billion tons per year. Examining the figures by country, we see that people in Sub-Saharan Africa, South as well as South East Asia only waste around 6-10 kg per person per year whereas Europeans and North Americans throw away between 95 and $115 \mathrm{~kg}$ of perfectly edible food (FAO 2011: v).

This pattern is repeated with other goods as well. In Britain around $30 \%$ of the contents of the average wardrobe has not been worn for at least a year, which gives us the figure of 1.7 billion items of clothing unused in the United Kingdom alone (Gracey/Moon 2012: 2).

In 2006, the McKinsey Global Institute calculated that the world's financial markets struggled to find investment opportunities for about 3.5 times global GDP at the time. This was the staggering figure of $\$ 167$ trillion in desperate liquidity (Farrell et al. 2008: 7) at the same time that the international community could not 
(and cannot) find enough money to supply sustainable energy, sanitation and food to a third of the world's population (Scharmer/Kaufer 2013: 94).

So, we can see that quite a bit of the capital (energy) is withdrawn from the system even though demand for more produced goods or use value is clearly there. The mainstream model of the economy in Fig. 3.3 does not capture this. But if the purchasing power among the poor does not meet capital owners' expectations of return on investment it will not flow there. Current 'growth' measurement standards are indifferent to such distributive effects. They count a euro that pays for a private jet as having created the same 'value' as one that pays for a ton of rice.

In rich countries slowing growth is usually equated with unemployment, the biggest threat to well-being. A team of economists at the Institute for Sustainable Development and International Relations (IDDRI) at the Science Po university in France has conducted a study on "A post-growth society for the twenty-first century. Does prosperity have to wait for the return of economic growth?" Here we find collated evidence about jobless growth, a disconnect between wage rises and productivity gains and a missing link between long-term growth and employment levels. The researchers conclude that political changes in labor policies, taxes, pension and health systems, and investment criteria would allow for much less growth-dependent societies in which individual and social prosperity are not compromised (Chancel et al. 2013).

So, sticking with the mantra in which endless economic growth is needed is a great way of avoiding the political responsibility and struggles that unlocking those path dependencies requires. This Herculean task is not helped by the perverse inequalities that the real rather than theoretical market logics, laws and institutions like our monetary system have created, overlooked or disguised by undifferentiated cost-benefit and growth analyses. In the United States, for example, decoupling productivity gains from real wage developments went hand in hand with lower taxation on capital and wealth. This cocktail has driven GDP to unprecedented heights and inequality levels back to those of the 1920s.

In a podcast for the Economist, Robert Reich, labor secretary under Bill Clinton and an economics professor explains: "Most of the economic gains in the past 25 years have gone to the top 15-20\% of Americans, but more recently, in the past six to seven years, most of the economic gains have gone to the top one percent.... The average CEO is making about 380 times more than the average worker-a huge gap relative to what it used to be 40 years ago - it was about 30 times" (Reich 2007). This interview predated the financial crisis, which has accelerated still further the rise in income of those controlling the factors of production.

One major cause of this trend has been documented by the OECD in its 2008 report Growing Unequal? Income Distribution and Poverty in OECD Countries. In countries where financial capital gains and self-employment income are taxed at lower rates than wages the pattern is clear: the top $20 \%$ keep on diverging from the middle classes and lower income strata. Real wages have stagnated in most of the OECD countries since the 1980 s and in many the trend is "moderate but significant" while some countries like Germany, Canada, Norway, the United States and Italy report 'significant' changes. 
The primary policy measure, especially for any longer-term correction of this structural discrimination, was outlined as follows: "Relying on taxing more and spending more as a response to inequality can only be a temporary measure. The only sustainable way to reduce inequality is to stop the underlying widening of wages and income from capital" (OECD 2008: 3). In this context it is interesting that the OECD report did not include the income of the super-rich because it would have been hard to measure by standard income indicators. What Thomas Picketty called the rentier class (2014) earns and manages its wealth differently.

The Tax Justice Network (TJN), a coalition of researchers and activists, estimated in 2012 that some $30 \%$ of global financial wealth was owned by the top $0.001 \%$ of the world's population or about 91,000 people. The next $19 \%$ was owned by the next $0.01 \%$, or 800,000 people and $32 \%$ belonged to the next $0.1 \%$, or 8 million people. This left $19 \%$ of the world's financial wealth for the remaining $99.9 \%$ of the world's population (TJN 2012: 5).

These numbers are probably utterly out of date by now. Oxfam International brought new calculations to the $2014 \mathrm{WEF}$ showing that the richest 85 people owned assets which amounted to the same value as those owned by the poorest 3.5 billion people. Since the report used numbers gleaned from the 'Forbes Billionaires List,' the magazine published an update three months later: the top tier had shrunk to 67 individuals.

The wealth of the wealthiest is growing so fast that the lists need monthly updates. Within one year, from 2013 to 2014, the threshold for qualification into the top 20 billionaires list jumped from $\$ 23$ to $\$ 31$ billion (Moreno 2014).

TJN went further and also examined levels of tax avoidance and the harmful impacts of tax competition and tax havens in offshore centers. In 2012 they published a report by James Henry, a former chief economist at McKinsey. According to him, at least \$21 trillion and possibly up to \$32 trillion of "unreported privately held financial wealth" is squirreled away in tax havens. This is a sum, "equivalent to the size of the United States and Japanese economies combined" (Henry 2012: 1). And this is only financial wealth. It excludes real estate, yachts and other non-financial assets owned via offshore structures.

Because this is unreported wealth, inevitably none of these sums have so far made it into the official statistics, so global wealth inequality is much higher than the data we usually draw upon suggests. In order to put the potential of redistributing existing wealth into perspective, TJN calculated how much a tax of $30 \%$ on a conservative estimate of $3 \%$ capital gains on those \$21-32 trillion would generate. The resulting \$190-280 billion is double the amount that the OECD countries combined spend on all overseas development assistance around the world (Henry 2012: 2). Additional taxes, for example, on inheritance, a wealth tax or a collection of tax avoided in years past would increase the numbers accordingly.

TJN estimates that the $\$ 21$ trillion belongs to no more than 10 million people who can afford a team of advisers specializing in the most effective ways of avoiding tax. This casts a very different light on scarcity, just distribution practices or proper formula for redistribution policies. The ahistorical ethics of no-net-loss is unmasked as just as half-baked as closed system physics. 
A future-oriented ethics and also management strategy was actually defined as part of sustainable development: sufficiency. Next to efficiency (no unnecessary waste) and consistency (solutions fit local-environmental-systems) this strategy is not so much technical but highly normative. It means embracing the idea that there can and should be enough production and consumption. Phrased this way it sounds like the baseline of sustainable development. Enough for everyone forever. Enough and not less, however, also means enough and not more. At least on one finite planet.

Yet, the economic thinking that is so overwhelmingly influential in politics and public discourse today simply excludes sufficiency from what could be a feasible solution. It is equated to a depression or moving back into caves. Moreover, it is often mainstream economists who declare that any idea of sufficiency, or no further economic growth in rich economies, would impair the 'human freedom' to invent, innovate and be creative. Not even in countries with stable population levels can their theory conceive of how living up to human potential would not lead to more market sales.

Critical conceptual environment and development thinkers like Wolfgang Sachs readily point out that only rich people can fall into the trap of seeing sufficiency solely as a regression. For every person living in deprivation and hunger the end of suffering is an aspiration (Sachs 2015: 2). In addition, Sachs continues, refraining from having more than enough might be less of an altruistic move, but instead a step toward justice and respect in a system where the overflow of wealth in some parts is directly connected to exploitation in others (ibid.).

The idea of providing enough for everyone within the carrying capacity of the planet was iconized in the 'doughnut' by Kate Raworth, UK researcher and campaigner for Oxfam in the run-up to the Rio+20 Summit. Her graph combines the Planetary Boundaries with minimum entitlements to social foundations to which every person on this planet should be granted access. The resulting 'doughnut' shows that there is a corridor or "safe and just operating space" in which development can be sustainably pursued.

The social foundations in Fig. 3.6 do not reflect a scientific assessment, but instead the results of what governments had stated to be their priorities in the run-up to the conference. They are therefore not definitive but illustrative. An understanding of the qualities of most important social foundations and of which governance solutions can most successfully embed them will become more precise with more research, just as the Planetary Boundaries will. Unfortunately, none of these empirical searches will be helped by mainstream economic approaches. In these approaches, only more monetary growth would mean that societies could pay for cleaning up the environment and grant some support to their unfit citizens-who could not otherwise survive. 


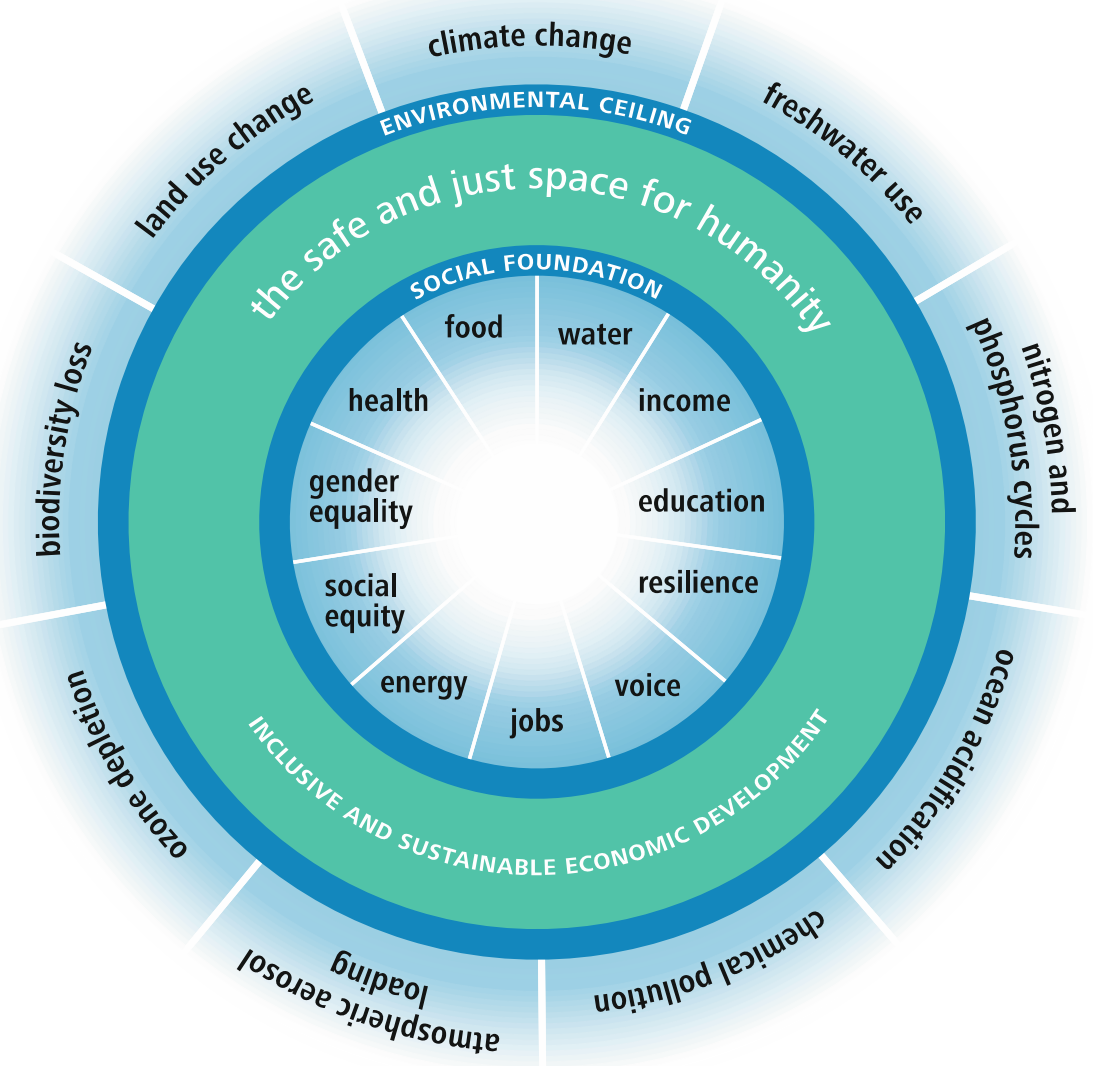

Fig. 3.6 The sustainable development doughnut. Source Based on Raworth (2012: 4)

\subsubsection{Unveiling the Money Magic}

On checking the statistics one can see that we do not have too little but far too much money racing around the globe. We live in a situation in which there is no lack of money but rather a lack of credit to fund real economic activity where it is needed. Instead, the search for trillions of dollars for good returns on investment causes frequent bubbles and economic instability. Sounds absurd? That is what I thought until I read good old Karl Marx. He explains how, in the context of the ascent of the mainstream economic paradigm, money has been given a peculiar function-a function that Polanyi acknowledged when he called it a fictitious commodity, but that economics textbooks overlook. It is very relevant when seeking to understand roadblocks to sustainable development. 
Money is typically portrayed as an equivalent value expression for all types of goods and services. It is defined as serving three functions. As a 'medium of exchange' it facilitates trade between goods. If a fisherman had to barter whatever he had caught directly for all the goods and services that he needed, it would require a lot of work, or luck, to find trading partners in possession of what he wanted, and they would also have to want fish in return. Money eases barter by dividing it into two transactions. The fisherman gets money for his fish from whoever wants the fish, and gives that money to whoever happens to offer what he himself wants. As a 'unit of account' money therefore allows the fisherman to measure the exchange value of what he has and to estimate how much of which good or service he can get on selling his produce. This also allows him to start planning a more complex fisheries enterprise and to use the money as a 'store of value' until he has saved enough, so that he can purchase another boat. During periods of low catches this also allows him to continue buying goods or services without having any fish to sell.

These three functions are listed in the mainstream textbooks. Here, exchange value and use value are directly linked. Each economic process involves investing money in order to produce an output whose value is higher than that of the single input factors. Savings or credit is applied to enable productive processes. The investor or creditor often participates in the generated surplus value for the prudence that saving money took or the risk that taking on a debt involves.

Thus goes the money story, and originally, as the term 'commodity money' expresses, there was something of real value behind it, e.g., beads or rare metals like gold. Marx's equation for this function of money goes as follows: C-M-C', or in other words commodities of a given value are available as input - one applies money to enable a process of combining them-commodities with higher value form the output (Marx 1887: 102-108).

This narrative is so strong that even today we think of money as something thing-like. But it was in fact a social innovation and over the course of the Great Transition stripped of any real use value, making it 'fiat money.' This type of money exists only because of government regulation. Its paper value tokens or numbers on computer screens have no real value at all. They are not real wealth but a claim on wealth and only function because you and the person or institution owing you the money accept this relational duty-or have to accept it by legal imposition.

So money is a relationship, as the root of the word credit-the Latin term credere or believing in-indicates. The paper notes of the Bank of England still have the following pledge on them: "I promise to pay the bearer on demand the sum of...." This type of money is a form of debt: Someone owes you something of real value. It is a promise of access to something one desires in the future.

With this innovation societies gave themselves the collective illusion that such faith-based wealth tokens could be transformed into any use value at any time. James Tobin (1918-2002), who won the Nobel Prize for economics in 1981, summarized this effect nicely: 
The community's wealth now has two components: the real goods accumulated through past real investment and fiduciary or paper 'goods' manufactured by the government from thin air. Of course the nonhuman wealth of such a nation 'really' consists only of its tangible capital. But, as viewed by the inhabitants of the nation individually, wealth exceeds the tangible capital stock by the size of what we might term the fiduciary issue. This is an illusion, but only one of the many fallacies of composition which are basic to any economy or any society. The illusion can be maintained unimpaired so long as society does not actually try to convert all of its paper wealth into goods (Tobin 1965: 676).

The beauty of this transformation was that there were far fewer limitations on the amount of money that could be created. But how did this impact the functions of money? This is the key question that Marx was looking at and he showed that the useful public good or social illusion was slowly but surely turned into a private commodity serving the accumulation of ever more financial wealth in any form.

For Marx, this was one of the essential and specific features of a capitalist market economy in comparison to other forms of market economies. His original use of the term 'capital' expresses the objectification of value in the form of financial 'products' that enable people to not only spend money on buying other commodities but also to apply it, with the sole aim of accumulating more money.

Marx expressed the difference by turning the normal money function around: C-M-C' (the purpose of money is to serve a higher input/output goal of creating something with more use value) becomes M-C-M' in which the purpose of money is to make more money. It is applied in any economic transaction that promises more exchange value and thus more financial return on investment (Marx 1887: 102-108). What is actually done in this process becomes secondary.

Prior to Polanyi's fictitious commodities, Marx showed how 'financial capital' becomes an input factor just like all the goods whose value it should express. The analogy expressing what he called a socioeconomic 'craziness' was the general genus of "the animal." Imagine a world in which it would suddenly come to life and interact with lions, tigers, rabbits and all the other creatures that this term had been created to subsume (Heinrich 2005, 76). Making money a 'value object' destined to be sold in markets is the incarnation of an abstract idea that turns debt into wealth.

This new commodity, however, is the most desirable of all as long as the conversion belief holds strongly. It does not rot, it needs little room for storage and promises to transform itself into any use value at any time. And for those with more money than their own need satisfaction requires, its application creates even more money without much actual work being required. In several languages we have the expression 'make your money work for you,' which refers to money invested purely to generate interest. This became a strong desire in accumulation-seeking individuals and soon we saw the emergence of private banks and lending organizations.

This is where the 'public good' concept of the way a financial sector should be set up was very beneficial, although it no longer reflects reality. Public goods serve all of society, so a financial sector designed from this perspective would have the role of ensuring that credit could flow where it was needed for use value generation. As a consequence, the fewer the costs involved in accomplishing this service, the 
better for society. So the financial sector should account for as small a percentage of total economic activity as possible (Dietz/O'Neill 2013: 110). The people working in it need to be paid for their managerial work since the actual value created for a society begins elsewhere, in the productive economy.

Does this resemble the financial system of today? Certainly not. The idea that finance is serving the economy is actively maintained, but increasing deregulation has allowed its institutions to do far more than matching the received money with credit needs. Today, private banks create a huge amount of the money themselves. While governments still control currency, over $90 \%$ of the money supply is issued by private, commercial banks and institutions that leverage the deposited amounts multiple times when issuing credit, i.e., debt (Daly/Farley 2010: 289-291).

Under the regulation of 'fractional reserve banking,' a bank only needs to have a small sum to be able to create big amounts of money. A reserve requirement of $10 \%$, for example, means that the bank can use a $\$ 100$ deposit to create $\$ 900$ in credit, out of which maybe $\$ 500$ will make it into another bank account leading to another $\$ 4500$ of new money, and so on. In some cases before the financial crisis of 2008 these reserves were as low as $2-3 \%$ or even zero.

Not all of this magically created money becomes productive credit by any means. Most of it circulates between financial institutions, while only a third of it enters the real economy (Scharmer/Kaufer 2013: 101-103). In practice this has meant that, in the last few decades, the amount of money in circulation has been growing much faster than the output of the real economy. Foreign exchange transactions of $\$ 1.5$ quadrillion outnumber international trade by a factor of 75 (Scharmer/Kaufer 2013: 94). This has led economists like Tobin (cited above) to demand a financial transaction tax that would slow such speculative flows down and provide some revenue that could be used by the government institutions safeguarding the public good image with gigantic bailouts or guarantees.

So the idea of turning money into a commodity and then stripping it of any real-world embodiment has led to what has been called the 'financialization' of economies: all value that is exchanged is captured, counted and expressed in monetary figures and thus easily transformed into financial instruments that can be traded in markets. Unsurprisingly the financial sector now contributes about $10 \%$ of GDP in countries like the United Kingdom and the United States, up from $2.3 \%$ in the 1950s (Ferguson 2008: 6).

Meanwhile, the excess of 'wealth' leads to an increase of prices of already existing assets like real estate and stocks, but not necessarily to the creation of new production and innovation that would bring new use value to where it is really needed. This was accelerated by making shareholder value the prime goal in corporate governance, and giving it greater importance than what is actually produced and how. But if money's purpose is to be applied for a good and quick financial return, risk calculations in comparison to the estimated profits speak against poor countries and people with non-Western legislation and a lack of purchasing power.

Behind this financialization trend and the increasing protection and privileging of investors lies, of course, the view that money, as capital, is a commodity or input factor equal to all the others. Of course it entitles its owner to a share of the 
generated surplus value. Some mainstream economists say that the investor is in effect paid for abstaining from the immediate utility gains that using the money for consumption would have brought, had he not lent it to someone else. Others would say that interest is necessary to incentivize paying back, and a justified premium for the risk involved in lending it to others.

All of this might have been true in times in which shareholders were also stakeholders and typically longer-term investors. Today, the vast majority of stocks are held by sharehoppers. Buying and selling within seconds is not really taking part in the entrepreneurial risk of a business. The traders doing it do not care what the companies do. Their algorithms track price developments and seek to gain from differences at times of purchase and selling. Whether the companies flourish or tank does not matter to them.

It does not come as a great surprise that profit making increasingly occurs for those inventing more and more financial instruments or 'products' like derivatives, credit default swaps, futures and options that are exchanged and traded in markets totally removed from the commodity world. We need a third equation: M-M-M'.

Financialization has several consequences from mind-sets to the structural drivers of development: the importance of financial motives and motivations increases in line with the influence of financial institutions, elites and markets in governing institutions. Big parts of the financial system today have lost any resemblance to the fiduciary role that Tobin foresaw. Trillions in desperate liquidity chase around the globe in search of good returns while money for development aid, climate protection or refugees cannot be found.

Meanwhile, the expectation of a constant return on each investment leads to compound interest developments that are simply absurd if one takes the long view of future generations. Garrett Hardin (1915-2003), a famous American ecologist, gave an example in 1985:

Suppose that the thirty pieces of silver Judas received for betraying Christ had been worth $\$ 30$; and suppose that he had put this into a bank account bearing $5 \%$ compound interest, payable in gold. Presuming the present price of gold, the initial capital would amount to 2.5 grams of gold. How long would it take for the Judas Account to be worth a weight of gold equal to the weight of the entire earth $\left(5.983 \times 10^{27} \mathrm{~g}\right)$ ? Just 1292 years (Hardin 1985: 72).

\subsubsection{Summary: Opening up Mainstream Economic Ideas Is Key for 'Our Common Future'}

Section 3.3 highlighted how the ideas and concepts summarized in Table 3.1 are among the root causes of financialization and its utterly unsustainable patterns of exploitation, allocation and accumulation. It showed what gets lost if these concepts provide the explanations and evidence for sustainability policymaking. Most importantly, it highlighted how the mind-sets and narratives building on these 
concepts encourage worldviews, personality structures and justification logics that might be very transformational, but not toward the goals and principles that the sustainable development agenda has adopted.

\begin{abstract}
"Economic thought systems matter because they are at the heart of an intellectual battle over the future direction of society," wrote MIT scholar Otto Scharmer and researcher Katrin Kaufer in their 2013 book on working toward more sustainable economies. The mainstream belief system, they continue, "has given Wall Street a de facto veto over public policy making that no other group or industry enjoys." Simon Johnson, another MIT professor and former IMF chief economist, is cited by them: "by 1998, it was part of the worldview of the Washington elite that what was good for Wall Street was good for America" (all from Scharmer/Kaufer 2013: 71).
\end{abstract}

The following summary is thus also the conclusion of this chapter. It briefly runs through the four big ideas listed in Table 3.1 and why they fall short when we seek to understand how to satisfy human needs while respecting nature's law. The discussions above have shown that they are scientifically flawed. Yet, through their materialization in today's market and government structures, these ideas have become very real in their impact on people, their decision-making and their freedom to do things differently and more sustainably.

The reflexive ontology behind this book sees the opening up of worldviews and belief systems as the first step in system innovation strategies: identify which arguments, practices or laws are built around flawed assumptions and ideas and understand how they hamper more sustainable developments. Engaging in transforming such path dependencies will of course always be a highly political, contested and power-ridden process whose outcome no one can predict. But shedding vested intellectual interests often comes before shedding economic vested interests: sense and legitimacy of the status quo start crumbling and alternative practices multiply, inspired by an emerging imaginary that there are indeed alternatives.

Trying to understand the world by dividing it into pieces creates an imaginary in which the relationships and generative rules underlying system dynamics get lost behind numbers and detailed descriptions of the individual pieces. This atomistic view of mechanical systems suggests that the single items remain unchanged and between them one can detect and thus manage linear and reproducible causalities in an additive or subtractive approach. System dynamics are viewed as predictable and controllable as long as the properties of the individual parts are understood well. There are no time delays or feedback loops that allow one to anticipate the fact that stopping a particular cause will no longer stop a particular reaction once system dynamics have reached tipping points. General ignorance of the Tyranny of Small Decisions is related to this: large output changes need large input changes. It is this 'particle' worldview or paradigm that leads to the common juxtaposition of incremental versus radical change.

But applying this view to complex systems filled with humans is not helpful, as the financial crises show. Using it to inform strategies of human need satisfaction offers very little insight about the matter it is supposed to address: utility or happiness is a relative and context-dependent experience and not a thing that can be privately held and hoarded. Meanwhile, natural capital is a web of life and not a 
stack of resources and services to be freely disassembled, reassembled and substituted.

Neither happiness nor nature qualify as 'pieces' whose properties stay the same if they are relocated. Nor can properties be easily reinstalled once single items have been taken out of their former setting. Understanding the world in systems, on the other hand, provides a very different understanding of the developments and their trajectories. Notions of tipping points, non-linear developments, delays and runaway effects, as well as irreversible changes and uncertainty enter the picture instead. This changes the perceptions of risk and even cost-benefit analyses tremendously. Adopting a precautionary approach becomes more of a rational strategy than one easily dismissed as anti-progress. This is the effect of paradigm shifts as described by Kuhn:

\begin{abstract}
... the historian of science may be tempted to exclaim that when paradigms change, the world itself changes with them. Led by a new paradigm, scientists adopt new instruments and look in new places. Even more important, during revolutions scientists see new and different things when looking with familiar instruments in places they have looked before. It is rather as if the professional community had been suddenly transported to another planet where familiar objects are seen in a different light and are joined by unfamiliar ones as well. ... In so far as their only recourse to that world is through what they see and do, we may want to say that after a revolution scientists are responding to a different world (Kuhn 1962: 111).
\end{abstract}

Understanding the world through quantifying and monetizing has subjected ever more areas of social being and collaboration as well as human-nature relations to the logic of markets. A non-market relationship or good is transformed into a commodity that is, from now on, compensated for with a payment, wage, rent or interest. It is now captured in economic statistics and an exchange value frame of willingness-to-pay enters the relation: the worth of everything is expressed in prices. Marglin dedicated his entire book to discussing how thinking like an economist undermines the earlier guiding principles and frames around those relations: people or communities who were formerly rather self-reliant and governed by reciprocity become dependent on market processes and the exchange values of their particular goods and services (Marglin 2010). With money come economistic mind-sets and financial motivations. The wider cultural meaning of work as a productive and caring activity is reduced to something done to make money.

While some may argue that this has delivered on a more efficient division of labor and specialization, it does not at all automatically mean that the relations and the quality of services like childcare, nursing, housework, etc., improves. Or that people enjoy their work more and perform better. At the same time, this way of thinking justifies anti-poor resentment because the lower the price of what one offers to society (i.e., the wage), the less worth it has. Therefore, having no job is viewed as a sign of not making enough effort.

Meanwhile, expanding financialization also means that the structural imperative of needing even more growth is expanded. Using interest-bearing or debt-based forms of money means that the borrower not only has to ensure an output that returns the input factor costs and his income in the form of profit, but also the 
interest he has to pay for the credit. Each enterprise owner therefore operates under constrained conditions when it comes to making production processes more sustainable, equitable or simply constant in output. Thanks especially to quarterly reporting and very short returns on investment expectations, they work with additional drivers toward the already high incentive to externalize environmental and social costs in weakly regulated competitive economies.

Regarding natural exploitation, Trucost, a green accounting specialist, has estimated that the world's 3000 largest corporations caused \$2.15 trillion in environmental damage in 2008 alone - and this did not register on their balance sheets (Trucost 2012). Imagine what internalizing these costs would mean for their profit warnings and thus stock values. So neither monetization nor market prices are neutral indicators or just allocation mechanisms, but are instead defined through highly political and power-laden processes.

Understanding the world by tracking accumulation of monetized values therefore keeps us from seeing where more productivity becomes void of productiveness and utility or where growth is causing irreversible damage in our ecosystems. Sociologist Harald Welzer describes the 'degrading' effect for humans:

This is the exact form in which work is understood in national economic theory: as an unlimited, endless activity that does not have a specific, limited, product-related objective, but is dedicated to the ceaseless creation of value - consequently the never-ending production of 'growth.' Marx referred to this process as the disappearance of concrete labor into exchange value (Welzer 2011: 22).

In affluent countries, as Jorgen Norgaard, professor at the Technical University of Denmark, has written, "much of the growth in GDP over the last years can be ascribed to pulling activities like child care, health care, cooking, entertainment, maintaining houses, etc. from the non-paid amateur economy into the professional economy" (Nørgård 2013: 63). All of these effects are part of what the decoupling agenda will measure: the economy 'immaterializes' itself. But nothing new has necessarily been created. Only the way it is done has changed.

The same things happen when corporations run by CEOs rather than owners gear their business toward increasing shareholder value, for example, through tactical issuance, sales and buying back of stocks. Big corporations now have huge internal financial departments whose only purpose is to increase the firm's market value and top executive pay is usually coupled directly to the firm's stock market value. For societies, however, exploding prices for stocks, houses, raw materials and land cannot count as a sign of real wealth generation, particularly if lower strata of society lose access to them. Instead, this type of 'growth' is a sign of too much liquidity and at the same time perpetuates its concentration even further. The by-catch are economic bubbles and instability.

Understanding the world by comparing and ranking all of the monetized price indicators instead of the underlying items does, however, mean that fictitious wealth can continue to grow for a long time. Capital substitutability thinking allows for Tobin's social myth to be stretched so far that consultancy firms like the Boston Consulting Group really issue forecasts like the following: "for Chinese children 
born in 2009, continued economic progress will mean that over the course of their lives, they can expect to consume thirty-eight times more material goods than their grandparents" (Asia Society 2012). Since 2010, the WEF's Global Risk Reports have, however, put water and food supply crises and rising greenhouse gas emissions among the top ten global risks of the next ten years. So while Chinese kids might keep on amassing financial capital, they could never transform it into 38 times more material goods.

Meanwhile, applying an exchange value or cost-benefit lens in all relations does affect human value judgments and our willingness to help, relate and feel connected to others and nature. One of the ongoing examples here is the cooptation of the idea of a 'Sharing Economy' by capitalist players. What started with the idea that people would make their use value items available to others (couchsurfing) has been pulled into the logics of exchange value. The mind-set of "what could I give to others to enjoy - or enjoy with them jointly' is transformed into a financialized mind-set of 'what can I get money for from others that I did not think of before now.' The enabling technologies might be the same but the intent and purpose behind these social innovations is completely different - as will be the relations emerging from it.

I therefore side with Heyman and Ariely who suggest "that compensations for employment and effort should be considered separately for social and monetary markets and that the level and type of compensation should be designed to fit the defined relationship" (Heyman/Ariely 2004: 793).

In conclusion we see how a blind emphasis on exchange value in mainstream accounting tools and standards has helped a situation to emerge in which the financial sector does not serve the real economy anymore, but rules it. It does that at a tremendously high cost to societies and sustainability. Of course, one might argue that people wishing to exert power and undercut societal agreements do so without taking the detour into mainstream economic thinking and models. But when it comes to rationalizing one's decisions, arguing them to the public and creating narratives in which particular interests seem compatible with an image of public benefit and good, they have performed a great service.

Also, the reflexive ontology presented in Chap. 2 has shown that biasing frames and selective interpretations of situations are an unavoidable aspect of human existence. They can be a conscious act of strategic framing or tactical misrepresentation of information. But when it comes to understanding the effect of paradigms and their shifting we talk about much deeper sociocultural transformations. Elinor Ostrom in her 2009 Nobel Prize lecture highlights how the - of coursepurely economic Homo economicus saga has impacted the design of institutions across the board:

Designing institutions to force entirely self-interested individuals to achieve better outcomes has been the major goal posited by policy analysts for much of the past half century. Extensive empirical research leads me to argue that instead, a core goal of public policy should be to facilitate the development of institutions that bring out the best in humans (Ostrom 2009: 435). 
So what could become the major goal instead? Summarizing twenty-first century research about human needs and how to align them with nature's qualities brings us very close to the differentiated framework of sufficiency of Sachs. He suggested it as early as the 1990s, and I did not anticipate this resemblance when I began to write the book.

For Sachs, sufficiency goes far beyond simply having less stuff. It tackles several unsustainable trends of the current development paradigm at once. In the framework he differentiates four 'E's' in German (Entschleunigung, Entflechtung, Entrümpelung, and Entkommerzialisierung), which I would translate as four 'D's': Deceleration, Deglobalization, Decluttering, and Decommodification. In a book on sufficiency policies another translator has called them the "four Lessens" because these concepts "express the idea that we need to lessen our speed, our distance, the encumbrance of our acquired possessions, and the role of commerce and the market in our lives" (Schneidewind/Zahrnt 2014: 30).

I like the four D's and summarize the key stance behind them by drawing on terms that were introduced and discussed in this chapter:

- Deceleration - endless efficiency and increasing speed in all areas of production and consumption reduce experienced utility and increase vulnerability of production chains;

- Deglobalization-price-driven fragmentation of production chains and transnational corporate units across the globe boosts profits but widely externalizes ecological costs and avoids fair taxation;

- Decluttering - running after ever more stuff in competition with others reduces the ability to really connect and enjoy each one of our items and also overstretches the Earth's carrying capacity;

- Decommercialization - applying mental models of commodities and financial benefits to all relationships leads to less quality of life, less concern for others or the environment, and keeps governance blind to the physical and psychological realities behind the numbers.

We can take more care of what we have, distribute it more sensibly and thoroughly, and innovate our production and consumption systems so they bring us into a safe and just operating space. There clearly is enough to go round. Spending patterns show that there is room for the reorientation of already existing wealth without ruining lives. We do not need ever more output. We need different business models, market patterns, money systems and the courage to let go of the exhausting narrative that we are insatiable egoists trapped in a constant competitive race over accumulation for accumulation's sake and a fear of falling behind.

The good news is that the wider context of what could shape into a Second Enlightenment movement holds this potential:

- Emphasis lies on reflexivity that takes circumstances into account when undertaking intellectual and empirical investigations.

- Social sciences and the role of spirituality return to the realms of understanding and explaining development patterns of the world. 
- Discourse around natural limits to growth meets an information technology revolution that could enable decentralized, resource-light well-being.

- Limits to private property and financialization are discussed as tenets for securing all citizens' freedoms and the functioning of democracy.

Where this type of thinking lies at the heart of developing businesses, towns, governments, and communities is the topic we turn to now.

Open Access This chapter is distributed under the terms of the Creative Commons Attribution 4.0 International License (http://creativecommons.org/licenses/by/4.0/), which permits use, duplication, adaptation, distribution and reproduction in any medium or format, as long as you give appropriate credit to the original author(s) and the source, provide a link to the Creative Commons license and indicate if changes were made.

The images or other third party material in this chapter are included in the work's Creative Commons license, unless indicated otherwise in the credit line; if such material is not included in the work's Creative Commons license and the respective action is not permitted by statutory regulation, users will need to obtain permission from the license holder to duplicate, adapt or reproduce the material. 